NÚÑEZ, Raúl; BELTRÁN, Ramón; SANTANDER, Nicolás, “Los hallazgos casuales en las diligencias de incautación e intervención de las comunicaciones digitales en Chile.

Algunos problemas"

Polít. Crim. Vol. 14, No 28 (Diciembre 2019), Art. 4, pp. 152-185.

[http://politcrim.com/wp-content/uploads/2019/11/Vol14N28A4.pdf]

\title{
Los hallazgos casuales en las diligencias de incautación e intervención de las comunicaciones digitales en Chile. Algunos problemas*
}

\section{The casual finding in the seizure and intervention procedures of digital communications in Chile. Some issues}

\author{
Raúl Núñez Ojeda \\ Doctor en Derecho, Universidad Pompeu Fabra (España) \\ Profesor de Derecho Procesal Civil y Procesal Penal, Pontificia Universidad Católica de \\ Valparaíso \\ raul.nunez@pucv.cl \\ Ramón Beltrán Calfurrapa \\ Doctor en Derecho, Pontificia Universidad Católica de Valparaíso (Chile) \\ Profesor de Derecho Procesal, Universidad de Atacama \\ ramon.beltran@uda.cl \\ Nicolás Santander Akkrass \\ Licenciado en Ciencias Jurídicas, Pontificia Universidad Católica de Valparaíso (Chile) \\ nicolas.santander@pucv.cl
}

\section{Resumen}

El presente artículo tiene por objeto denotar el rol de los denominados "hallazgos casuales" en las diligencias investigativas de incautación y registro de las comunicaciones digitales en Chile. Para tales efectos, luego de efectuar un breve análisis del principio de proporcionalidad y su relevancia en el tratamiento argumentativo de tal instituto, el trabajo aborda los hallazgos casuales desde una triple consideración: en primer término, realizando un análisis conceptual y metodológico de los hallazgos casuales en consideración a sus principales manifestaciones en el Derecho comparado, particularmente en países como Alemania, Italia y España; en segundo término, examinando los hallazgos casuales en Chile y sus manifestaciones jurisprudenciales más significativas, a partir de los artículos 215 (referido a la diligencia de entrada y registro) y 223 (relativo a la interceptación de comunicaciones telefónicas) del Código Procesal Penal; y, por último, abordando los hallazgos casuales de las comunicaciones digitales en nuestro país, sus problemas prácticos más relevantes, así como sus posibles formas de solución.

\footnotetext{
*Este trabajo se enmarca dentro del proyecto FONDECYT regular $\mathrm{N}^{\circ} 1130422$, que lleva por título: "Formulación de una teoría general de las medidas coercitivas en el proceso penal chileno: estudio dogmático y crítico", cuyo investigador principal es el profesor Dr. Guillermo Oliver Calderón de la Pontificia Universidad Católica de Valparaíso.
} 


\title{
Polít. Crim. Vol. 14, No 28 (Diciembre 2019), Art. 4, pp. 152-185. [http://politcrim.com/wp-content/uploads/2019/10/Vol14N28A4.pdf]
}

Palabras clave: Hallazgos casuales, derechos fundamentales, principio de proporcionalidad

\begin{abstract}
The purpose of this article is to analyze the role of the so-called casual discoveries in the investigative proceedings of seizure and registration of digital communications in Chile. To achieve that goal, after making a brief analysis of the principle of proportionality and its relevance in the argumentative treatment, the work approaches the casual discoveries from a triple consideration: firstly, doing a conceptual and methodological analysis of the casual discoveries in consideration of its main manifestations in Comparative Law, particularly in countries such as Germany, Italy and Spain; secondly, examining casual discoveries in Chile and its most significant jurisprudential manifestations, based on articles 215 (referring to the entry and search procedure) and 223 (regarding the interception of telephone communications) of the Criminal Procedure Code; and, finally, tackling the casual discoveries of digital communications in Chile, its most relevant practical problems, as well as its possible ways of solution.
\end{abstract}

Key words: Casual findings, fundamental rights, proportionality principle

\section{Planteamiento general del tema}

Para nadie a estas alturas puede resultar vana la necesidad de tomarse los hallazgos casuales en serio. $\mathrm{Y}$ es que, no obstante estar durante mucho tiempo relegados casi a un segundo plano, poco a poco han logrado notoriedad por su cada vez más frecuente ocurrencia práctica. En efecto, en los últimos años han ido apareciendo entre nosotros un número no menor de investigaciones penales en las cuales, producto de alguna medida intrusiva judicialmente decretada, se descubren de forma casual y fortuita evidencias que demuestran la realización de un hecho punible distinto del que en principio se estaba investigando. Ello, como es de prever, no sólo ha involucrado el cuestionarse el valor y mérito de dichas fuentes de prueba, sino que también -y preferentemente- el volver a poner sobre la palestra la clásica tensión existente entre la tarea del Estado de investigar todo hecho constitutivo de delito, por un lado, y la de respetar los derechos fundamentales del imputado, por otro.

En efecto, sabido es que la investigación penal constituye un constante ejercicio de formulaciones intelectuales, planteamiento de conjeturas y elaboración de posibles hipótesis que se correspondan con aquella parte de los hechos que es susceptible de ser verificada a través de la prueba. El desarrollo de este ejercicio ya evidencia que la justicia y especialmente la penal- se encuentra íntimamente asociada a la búsqueda de la "verdad". Luego, no se trata de una verdades absolutas, metafísicas ni menos aún religiosas, sino de una actividad con un alcance mucho más modesto y limitado: la finalidad de la prueba como institución jurídica es la de permitir alcanzar el conocimiento probable y circunstancial de los enunciados fácticos del caso. ${ }^{1} \mathrm{Y}$ esto es así sencillamente por dos

\footnotetext{
${ }^{1}$ Aquí seguimos la opinión de D'AGOSTINI, Franca, "L'uso scettico della verità", en: FORTI, GabrioVARRASO, Gianluca; CAPUTO, Matteo (eds.), «Verità» del precetto e della sanzione penale alla prova del processo, Milano: Jovene editore, 2014, pp. 25-62, passim.
} 
razones. La primera, porque el conocimiento en materia procesal nunca es pleno ni absoluto, sino que está siempre supeditado a la probable ocurrencia de los hechos en atención a la cantidad y calidad de información disponible. La segunda, porque si somos conscientes de la falibilidad de los procedimientos que utilizamos para el descubrimiento tal verdad, debemos coincidir con que el rol institucional del proceso no permite una actividad investigativa completamente libre y soberana del ente persecutor. Por consiguiente, aunque el proceso penal se oriente a la búsqueda de la verdad, al Derecho procesal penal no le interesa sólo y exclusivamente la averiguación de la verdad, sino también la protección de otros fines que cabría calificar como "contra-epistémicos". De este modo, como bien lo expresó el Tribunal Supremo Alemán -BGH-, en su conocida sentencia del 14 de junio de 1960:

"no hay principio alguno del ordenamiento procesal penal que imponga la investigación de la verdad a cualquier precio"."

Ahora bien, que el Derecho procesal penal persiga fines independientes de la búsqueda de la verdad es una cuestión que no siempre ha resultado autoevidente. De hecho, independientemente de las concretas excepciones, es notorio que los sistemas jurídicos continentales se han caracterizado históricamente por dar un mayor realce a la búsqueda de la verdad por sobre los derechos del imputado. No por nada, incluso después de los albores de la Ilustración y del Code d'Instruction criminelle de 1808, la mayoría de los países europeos y latinoamericanos conservaron la prevalencia del sistema inquisitivo en la fase de instrucción a fin de indagar precisamente a profundidad la notitia criminis.

Sin embargo, quizá ya antes pero sobre todo -y de modo muy apreciable- a partir de la segunda mitad del siglo XX, se fueron incorporando en nuestro medio ciertas "formas" garantísticas limitativas de la averiguación de la verdad. Y ello no sólo como una forma de instaurar un freno y contrapeso respecto del uso desmesurado del principio inquisitivo, sino que también -y preferentemente- como un método para salvaguardar derechos y garantías fundamentales. De ahí que, en lo sustancial, toda diligencia investigativa que afecte potencialmente derechos fundamentales, como por ejemplo, los allanamientos de domicilios, las incautaciones de especies y, en general, las medidas de entrada, registro e incautación ${ }^{3}$, requieran de una autorización judicial previa especialmente motivada y

\footnotetext{
${ }^{2}$ BGHS 14, 358 (365). En idéntico sentido, del mismo tribunal, Cfr. BGHS 58, 301 (309); 51,285 (290); 38 , 372 (374); 38, 214 (220); 31, 304 (309); 14, 358 (365). Antes, en todo caso, refiriéndose a las prohibiciones probatorias como límites a la investigación de la verdad, Cfr. BELING, Ernst, Die Beweisverbote als Grenzen der Wahrheitsfindung im Strafprozess, Breslau: Schletter, 1903, pp. 2 y ss. Para la versión en castellano de dicho trabajo, Cfr. BELING, Ernst, "Las prohibiciones probatorias como límites de la averiguación de la verdad en el proceso penal", en: BELING, Ernst; AMBOS, Kai; GUERRERO, Oscar Julián, Las prohibiciones probatorias, Bogotá: Temis, 2009, pp. 3-56, passim.

${ }^{3}$ En relación con diligencias de entrada, registro e incautación, se pueden revisar, entre otros, los siguientes trabajos: ÁLVAREZ RODRÍGUEZ, José Ramón; RIUS DIEGO, Francisco José, La entrada y registro en lugar cerrado: consideraciones procesales, jurisprudenciales y policiales, Madrid: Tecnos, 2009, passim; KONRAD, Sabine, Die Beschlagnahme von Verteidigungsunterlagen, Frankfurt am Main: Peter Lang, 2000, passim; LA FAVE, Wayne R., "Pinguitudinous Police, Pachydermatous Prey: Whence Fourth Amendment Seizures?", U. Ill. L. Rev. (1991), pp. 729 y ss, passim; LA FAVE, Wayne R., Search and Seizure, § 9.4, 2004, passim; MACLIN, Tracey, "Black and Blue Encounters- Some Preliminary Thoughts About Fourth
} 


\section{Polít. Crim. Vol. 14, № 28 (Diciembre 2019), Art. 4, pp. 152-185. [http://politcrim.com/wp-content/uploads/2019/10/Vol14N28A4.pdf]}

justificada, a objeto de constatar la ocurrencia de determinadas circunstancias fácticas relevantes para la investigación.

Con todo, y dejando aparte los epígonos "puros" sobre la licitud de la prueba, resulta claro que el descubrimiento determinadas fuentes de prueba no buscadas "ex profeso" plantea una serie de dificultades a los diversos operadores jurídicos. Y ello no sólo por los derechos fundamentales involucrados, como la intimidad, la inviolabilidad del domicilio o el secreto de las comunicaciones, sino que también porque resulta casi contraintuitivo dejar de investigar "todos" los delitos que surgen precisamente a partir de la investigación de otros delitos. Por tal motivo, y sin pretensión de exhaustividad, en el presente trabajo pretenderemos sacar a la luz algunas dificultades que surgen justamente cuando se ponen en relación estos dos bloques de cuestiones. Para ello, en primer término, luego de efectuar un breve análisis del principio de proporcionalidad y su relevancia en el tratamiento argumentativo de los hallazgos casuales, decantaremos metodológicamente las nociones básicas de dichos hallazgos y sus diversas manifestaciones en el Derecho comparado. Luego, en segundo lugar, procederemos a analizar los hallazgos casuales en Chile y los criterios más usuales esgrimidos por la jurisprudencia para afrontar sus diversos dilemas. Por último, y al alero de las diligencias investigativas de incautación y registro de las comunicaciones digitales, intentaremos demostrar de forma prescriptiva cómo y de qué forma podría otorgársele mérito probatorio a los citados hallazgos casuales y cuál debiese ser el modo más plausible para ponderar sus diversos efectos.

\section{El principio de proporcionalidad}

"Sólo el logro de un bien supremo para el todo puede dar derecho al Estado a exigir el sacrificio de un bien menor del individuo. Mientras la preponderancia no sea evidente, la libertad natural debe prevalecer"4.

Con estas palabras, el jurista prusiano Carl Gottlieb Svarez (1746-1798), en sus famosas "Conferencias sobre el Derecho y el Estado" de 1791-1792, llamaba la atención de la comunidad académica europea, sintetizando, ínsitamente, la necesidad de dar cabida a la proporcionalidad como una idea vinculada a la ponderación entre los intereses públicos y

Amendment Seizures: Should Race Matter?", Val. U. Rev. (1991), pp. 243 y ss, passim; MARTÍNEZ PARDO, Vicente, "La práctica de la entrada y registro domiciliario", Revista Jurídica Magestri et Doctores $\mathrm{n}^{\circ} 8$ (2002) 2, passim; NADLER, Janice, No Need to Shout: Bus Sweeps and the Psycology of Coercion, Sup. Ct. Rev., 2001, pp. 153-222, passim; PARK, Tido, Durchsuchung und Beschlagnahme: $2^{a}$ edición, München: Beck, 2009, passim; RIVES SEVA, Antonio Pablo, La diligencia de entrada y registro domiciliario, Barcelona: Bosch S.A., 2004, passim; ROXIN, Claus, "Zur richterlichen Kontrolle von Durchsuchungen und Beschlagnahmen", Strafverteidiger (1997), pp. 654-656, passim; SKLANSKY, David Alan, "On Train May Hide Another: Katz Stonewall, and the Secret Subtext of Criminal Procedure", U.C. Davis L. Rev. (2008), pp. 875 y ss, passim; TOMKOVICZ, James J., "Beyond Secrecy for Secret's Sake: Toward an Expanded Vision of the Fourth Amendment Privacy Province", Hasting Law Journal n³6 (1985), pp. 645-737, passim; ZAVIDICH DIOMEDI, Carolina, "El registro de vehículos", Revista Jurídica del Ministerio Público, n³8 (2009), pp. 147-156, passim.

${ }^{4}$ ["Nur die Erreichung eines uberwiegenden Guts fur das Ganze kann den Staat berechtigen, die Aufopferung eines minderen Guts von dem einzelnen zu fordern. Solange das Ubergewicht nicht evident ist, muB es bei der narurlichen Freiheit bleiben"]. GOTTLIEB SVAREZ, Carl, Vorträge über Recht und Staat. Cologne: Westdeutscher Verlag, 1960, p. 39. 
los derechos naturales del individuo. ${ }^{5}$ Por supuesto, desde dicha época hasta la fecha, tal principio se ha ido asentando progresivamente al punto de constituir un fenómeno con una estructura e identidad propia, merced los diversos aportes doctrinales y jurisprudenciales desarrollados principalmente la segunda mitad del Siglo XX.

En efecto, sabido es que luego de la Segunda Guerra Mundial, se expidieron textos constitucionales con amplios mandatos sustantivos para el Estado, reconociéndose una gran cantidad de derechos fundamentales para las personas. Sin embargo, bien pronto se observó que una auténtica democracia liberal, en tanto forma de gobierno destinada a dar prioridad a tales derechos, tiene que aceptar, si quiere viabilidad y estabilidad, una buena dosis de restricciones en el ejercicio legítimo de tales prerrogativas. ${ }^{6}$ Ello, pues, en los hechos, difícilmente se puede pensar que la conducta de un individuo en sociedad, en mayor o menor grado, no llegue a afectar los intereses legítimos de otros conciudadanos. Sucede, sin embargo, como diría Nozick, que los derechos fundamentales se pensaron en una lógica completamente distinta: en la idea de fijar "límites" o "restricciones laterales" a la persecución de objetivos sociales colectivos; ${ }^{7}$ en la mecánica de impedir que se prive a los individuos de ciertas prerrogativas a pretexto de que con ello, de una u otra forma, se beneficie a otros miembros de la colectividad estatal. De ahí que, por consiguiente, se haya comprendido que los derechos fundamentales no pueden ser satisfactoriamente abordados solo a partir de una lógica global de coste-beneficios, sino que requieren de un "balance" razonado y justificado que permita avalar - caso a caso- una eventual restricción legítima en su ejercicio.

Pues bien, a partir de la consolidación de tales apreciaciones, el discurso teórico y cívico sobre los derechos fundamentales se desvió desde su constitucionalización hacia su efectiva puesta en práctica. De este modo, asumiendo que los derechos individuales no deberían, si es que se les reconoce como tales, ser considerados meros intereses que pueden ser sacrificados en pos de meras circunstancias agregativas, poco a poco diversos tribunales constitucionales fueron acuñando la idea de proporcionalidad como una herramienta hermenéutica y argumentativa clave para entender el ejercicio y la restricción de los

\footnotetext{
${ }^{5}$ Para la historia evolutiva de la idea de proporcionalidad, Cfr. ENGLE, Eric, "The history of the general principle of proportionality: an overview", The Dartmouth Law Journal n ${ }^{\circ} 10$ (2012), pp. 1-11, passim; BARAK, Aharon, Proportionality: Constitutional rights and their limitations, Cambridge: Cambridge University Press, 2012, pp. 175 y ss, passim; STONE SWEET, Alec; MATHEWS, Jud, "Proportionality balancing and global constitutionalism", Columbia Journal of Transnational Law n⿳47 (2008) n n 73, pp. 98 y ss., passim.

${ }^{6}$ Recuérdese, en todo caso, que esta idea se encuentra ya en el artículo $4^{\circ}$ de la Declaración de los Derechos del Hombre y el Ciudadano de 1789: "La liberté consiste à pouvoir faire tout ce qui ne nuit pas à autrui: ainsi, l'exercice des droits naturels de chaque homme n'a de bornes que celles qui assurent aux autres membres de la société la jouissance de ces mêmes droits. Ces bornes ne peuvent être déterminées que par la loi".

${ }^{7}$ Por ello, según explica NOZICK: "Side constraints upon action reflect the underlying Kantian principle that individuals are ends and not merely means; they may not be sacrificed or used for the achieving of other ends without their consent. Individuals are inviolable". NOZICK, Robert, Anarchy, State and Utopia, Oxford: Blackwell Publishers, 2001, pp. 30-31.
} 


\section{Polít. Crim. Vol. 14, No 28 (Diciembre 2019), Art. 4, pp. 152-185. [http://politcrim.com/wp-content/uploads/2019/10/Vol14N28A4.pdf]}

derechos fundamentales. ${ }^{8}$ Así, por ejemplo, de acuerdo con una decisión del 15 de diciembre de 1965, el Tribunal Constitucional Federal Alemán -BVerfGE- sostuvo enfáticamente:

"En la República Federal Alemana el principio de proporcionalidad tiene rango constitucional. Éste principio tiene su fundamento en el principio del Estado de Derecho y en la esencia de los mismos derechos fundamentales que, como expresión del derecho general del ciudadano a la libertad frente al Estado, sólo puede ser limitado en forma amplia por el poder público cuando ello sea indispensable". 9

En este contexto, asumiéndose entonces como un criterio metodológico de vital importancia, el principio de proporcionalidad fue paulatinamente desarrollándose con una clara finalidad: pretender que cualquier órgano del Estado cumpla sus tareas hermenéuticas en materia de derechos fundamentales de una manera lo más racional posible ${ }^{10}$. Este principio, por ende, pasó a representar una pauta argumentativa que facilita a los intérpretes justificar sus decisiones interpretativas en materia de derechos fundamentales y, de este modo, poder suministrar razones a favor y en contra de determinadas afectaciones iusfundamentales. ${ }^{11}$ No restringe su campo de acción, por consiguiente, sólo a materias administrativas o constitucionales -como en sus orígenes-, sino que se manifiesta en cualquier ámbito del ordenamiento jurídico por su clara ascendencia con el efecto de “irradiación de los derechos fundamentales". ${ }^{2}$ Y la razón de esto es casi evidente. Los

${ }^{8}$ Cfr. CARBONELL, Miguel, "Presentación. El principio de proporcionalidad y los derechos fundamentales", en CARBONELL, Miguel (coord.), El principio de proporcionalidad en la interpretación jurídica, Santiago: Librotecnia, 2010, pp. 11-15, p.12.

9 [“In der Bundesrepublik Deutschland hat der Grundsatz der Verhältnismäßigkeit verfassungsrechtlichen Rang. Er ergibt sich (...) aus dem Rechtsstaatsprinzip, im Grunde bereits aus dem Wesen der Grundrechte selbst, die als Ausdruck des allgemeinen Freiheitsanspruchs des Bürgers gegenüber dem Staat von der öffentlichen Gewalt jeweils nur so weit beschränkt werden dürfen, als es zum Schutz öffentlicher Interessen unerläßlich ist”]. BVerfGE 19, 342 (1965).

${ }^{10}$ De hecho, aunque con atisbos en la antigüedad, el término proporcionalidad "Verhältnismäßigkeit" aparece recién la segunda mitad del siglo XIX en Prusia precisamente evocando la idea de "razonabilidad". Así, según explica Singh: "Literally Verhältnismäßigkeit may be translated as proportionality. But proportionality does not convey the true meaning and import of the German word 'Verhältnismäßigkeit'. The closest but not an exact correspondence can be found in the word reasonableness and therefore the principle of verhältnismäßigkeit has a close but not an exact correspondence in the common law principle of reasonableness whose antecedents are traced back to late sixteenth century and has recently emerged as an independent and important ground for examining the validity of administrative actions". SINGH, Mahendra P., German Administrative Law in Common Law Perspective, Berlín: Springer, 1985, p. 88.

${ }^{11}$ Cfr. LOPERA MESA, Gloria, "Principio de proporcionalidad y control constitucional de las leyes penales", en CARBONELL, Miguel (coord.), El principio de proporcionalidad en la interpretación jurídica, Santiago: Librotecnia, 2010, p. 211-256, p. 212.

${ }^{12}$ Sobre el efecto de irradiación de los derechos fundamentales, considérese, de modo particular, el famoso fallo "Lüth" adoptado por el Tribunal Constitucional Federal Alemán, el 15 de enero de 1958, en el cual enfáticamente se sostuvo: “(...) La Ley Fundamental, que no quiere ser un orden neutral de valores (...), ha establecido también en la parte dedicada a los derechos fundamentales un orden objetivo de valores y que precisamente con ello se pone de manifiesto un fortalecimiento por principio de la pretensión de validez de los derechos fundamentales(...). Este sistema de valores, que encuentra su núcleo en la personalidad humana que se desarrolla libremente en el interior de la comunidad social y en su dignidad, debe regir, en tanto que decisión constitucional básica, en todos los ámbitos del derecho; la legislación, la administración y la jurisprudencia reciben de él directrices e impulso”. [“(...) Grundgesetz, das keine wertneutrale Ordnung sein will (...) in seinem Grundrechtsabschnitt auch eine objektive Wertordnung aufgerichtet hat und daß gerade 
derechos fundamentales, como principios constitucionales objetivos, despliegan sus efectos en todas las direcciones y áreas del Derecho, también, y especialmente, horizontalmente entre los miembros de la comunidad jurídica, ${ }^{13}$ y son inherentemente indeterminados en su alcance e intensidad. De hecho, se aplican a diferentes dimensiones de libertad y protección que no necesariamente se ejecutan en paralelo, ni tampoco trabajan homogéneamente en función de un mismo destinatario o titular común. Como resultado, los derechos fundamentales ostentan una clara tendencia hacia la asimetría. De ahí que, como bien explica Böckenförde,
"si no se equilibran las reclamaciones en competencia, ciertos contenidos de derechos fundamentales se expandirían unilateralmente a expensas de otros contenidos de derechos fundamentales o con respecto a otros portadores de derechos fundamentales. Precisamente por eso es imperativo incorporar el principio de proporcionalidad en la aplicación del contenido de los derechos fundamentales en el Derecho objetivo". ${ }^{14}$

Ello explica, entonces, que países tanto del "civil law" como del "common law", organismos internaciones, así como diversos tribunales internaciones, hayan reconocido en el principio de proporcionalidad no sólo el mérito de servir de base para equilibrar posibles reclamaciones iusfundamentales en conflicto, sino que también por contribuir -a través de un conjunto estructurado y analíticamente coherente de criterios- en el fortalecimiento de las democracias contemporáneas. ${ }^{15}$

Con todo, a partir de lo anterior, es claro que el principio de proporcionalidad reclama especial vigencia dentro del proceso penal. En efecto, sabido es que frente a la comisión de un hecho considerado como delictivo, mientras el Derecho penal se ocupa de los elementos que fundamentan el merecimiento y la necesidad de la pena -0 una eventual medida de seguridad-, el Derecho procesal penal atiende a un conjunto de órganos y procedimientos encaminados a averiguar el contenido de verdad probable de tal circunstancia delictiva. De esta forma, el Derecho procesal penal debe lidiar con el individuo concreto; con la persona de carne y hueso que, en definitiva, deberá soportar una privación o restricción de sus derechos fundamentales más básicos. ${ }^{16}$ De allí, entonces, la necesidad de reconocer al principio de proporcionalidad como un instrumento heurístico, como una herramienta metodológica esencial que facilita la conciliación de intereses opuestos: por un lado, el

\footnotetext{
hierin eine prinzipielle Verstärkung der Geltungskraft der Grundrechte zum Ausdruck kommt (...). Dieses Wertsystem, das seinen Mittelpunkt in der innerhalb der sozialen Gemeinschaft sich frei entfaltenden menschlichen Persönlichkeit und ihrer Würde findet, muß als verfassungsrechtliche Grundentscheidung für alle Bereiche des Rechts gelten; Gesetzgebung, Verwaltung und Rechtsprechung empfangen von ihm Richtlinien und Impulse”]. BVerfGE 7, 198 (1958).

${ }^{13}$ Sobre el efecto horizontal de los derechos fundamentales, Cfr. ALEXY, Robert, Teoría de los derechos fundamentales, $2^{a}$ edición, Trad.: BERNAL PULIDO, Carlos, Madrid: Centro de Estudios Políticos y Constitucionales, 2008, pp. 464 y ss.

${ }^{14}$ BÖCKENFÖRDE, Ernst- Wolfgang, "Fundamental rights as constitutional principles. On the current state of Interpreting fundamental rights”, en: KÜNKLER, Mirjam; STEIN, Tine (eds.), Constitutional and political theory: selected writings, vol. I, Oxford: Oxford University Press, 2017, pp. 235-265, p. 254.

${ }^{15}$ En argumento, Cfr. COHEN-ELIYA, Moshe; PORAT, Iddo, "Proportionality and justification", Law Journal University of Toronto $\mathrm{n}^{\circ} 64$ (2014) 3, pp. 458-477, pp. 458 y ss.

${ }^{16}$ BELING, Ernst, Derecho Procesal Penal, Trad.: FENECH, Miguel, Barcelona: Ed. Labor, 1943, p. 2.
} 


\section{Polít. Crim. Vol. 14, No 28 (Diciembre 2019), Art. 4, pp. 152-185. [http://politcrim.com/wp-content/uploads/2019/10/Vol14N28A4.pdf]}

interés estatal por ejercer el ius puniendi, vale decir, la persecución penal llevada a cabo por Ministerio Público; y, por otro, el interés del imputado por defender su "ius libertatis". 17

Sin embargo, el rol del principio de proporcionalidad en el campo procesal penal tampoco se agota allí. De hecho, detrás de él confluye la necesidad de un control constante en la justificación que se esgrime como base para la restricción de cualquier derecho fundamental. Piénsese, en este sentido, en la posibilidad de valorar una grabación audiovisual privada, llevada a cabo en el marco de una investigación penal, en razón de la existencia de ciertos "indicios" considerados delictivos; o en la decretación de una prisión preventiva, ordenada para el supuesto éxito de una investigación, pero sin la debida articulación justificativa de sus elementos materiales y cautelares. En todos estos casos, si bien las razones o justificaciones que esgrima el juez de garantía son extrínsecas al concepto mismo de proporcionalidad, ésta contribuye metodológicamente a fijar el camino analítico más apropiado para armonizar tales casos. ${ }^{18}$ Primero, distinguiendo entre las cuestiones relativas al supuesto de hecho del derecho involucrado y las cuestiones relativas a la justificación de la restricción que se le pretende irrogar. A continuación, permitiendo elucidar el fin de la medida restrictiva, la conexión racional entre ésta y la limitación del derecho, así como la necesidad de la medida frente a la ausencia de otros medios igualmente eficaces para alcanzar el fin que se pretende. Y, por último, constatando una relación adecuada de equilibrio entre el beneficio perseguido por la medida restrictiva y la vulneración efectiva causada al derecho fundamental de que se trata. ${ }^{19}$ En otras palabras, una vez constatado el supuesto de hecho del derecho, así como su concreto ámbito normativo de protección, el juez de garantía debiese examinar que se verifiquen tres requisitos copulativos a su haber, esto es: idoneidad, necesidad y proporcionalidad en sentido estricto. Por lo tanto, en la medida en que estemos ante un derecho de ejercicio relativo, esto es, un derecho cuyo ámbito de protección permita una restricción legítima en su ejercicio, ${ }^{20}$ el test de proporcionalidad se desenvolverá de manera sucesiva y escalonada a fin de evitar, precisamente, un sacrificio innecesario o excesivo que lesione el contenido esencial del derecho fundamental ponderado.

\footnotetext{
${ }^{17}$ Cfr. GONZÁLEZ-CUELLAR SERRANO, Nicolás, Proporcionalidad y derechos fundamentales en el proceso penal, Madrid: Colex, 1990, p. 17.

${ }^{18}$ Así, como expresa Fordham: "Proportionality can provide the neatest analytical way forward for all these cases. After all, proportionality is itself a sliding scale (...), and it would be expected that some interests arising in some contexts would call for a greater degree of scrutiny. In these circumstances, there is no need for a tool for testing "justification” other than that of proportionality". FORDHAM, Michael, "Common law proportionality", Judicial Review n'7 (2002) n 2, pp. 110-123, p. 121.

19 Sobre tal proceder argumentativo en la proporcionalidad, Cfr. KHOSLA, Madhav, "Proportionality: An assault. On human rights?: A reply”. International Journal of Constitutional Law n8 (2010) 2, pp. 298-306, p. 299.

${ }^{20}$ Considérese, en este sentido, que gran parte de la doctrina constitucional moderna califica la mayoría de los derechos fundamentales como de ejercicio relativo. De hecho, incluso el derecho a la vida, que se supone uno de los derechos más importantes y trascendentes del sistema jurídico, se encuentra sometido a una serie de "restricciones" o "limitaciones", derivadas, por ejemplo, de circunstancias propias de la legítima defensa o del estado de necesidad. De ahí que sean pocos y escasos los derechos de ejercicio absoluto. Desde esta óptica, sin embargo, un caso paradigmático de derecho absoluto sería, según GEWIRTH, "the right of a mother not to be tortured to death by her". GEWIRTH, Alan, "Are there any absolute rights?", The Philosophical Quarterly n³1 (1981) n 122, pp. 1-16, passim.
} 
En idéntica línea de pensamiento, en nuestro país, el Tribunal Constitucional ha enfatizado:

"Que el principio de proporcionalidad, también conocido como "máxima de razonabilidad" o "principio de prohibición de exceso", es uno de los estándares normativos empleados por la jurisdicción constitucional para determinar la validez de una interferencia en el ejercicio legítimo de un derecho fundamental, en virtud del cual se examina la idoneidad, necesidad y proporcionalidad estricta de la medida que interfiere con el derecho. (...) Y agrega la doctrina que el principio de proporcionalidad exige que una medida limitativa de derecho se ajuste a un fin previamente determinado. La medida debe ser idónea para la consecución del fin pretendido (juicio de idoneidad). El segundo aspecto del principio de proporcionalidad exige la adopción de la medida menos gravosa para los derechos que se encuentran en juego. En otros términos, que la medida restrictiva sea indispensable para lograr el fin deseado y sea la menos gravosa para el derecho o libertad comprometidos, frente a otras alternativas existentes (juicio de necesidad). Por último, a la proporcionalidad en sentido estricto se la percibe como un mandato de ponderación. Es el caso cuando existen principios en pugna, en el evento de que la ley de colisión exija que se ponderen los intereses en juego. En conclusión, debe asumirse que determinadas valoraciones deben hacerse para establecer una relación de prevalencia entre los principios en juego". ${ }^{21}$

Por tanto, antes de decretar cualquier medida restrictiva de derechos fundamentales en materia procesal penal, el juez de garantía debiese efectuar un test de proporcionalidad a objeto de favorecer el marco argumentativo de sus decisiones interpretativas y, de este modo, sustentar un orden metodológico de manera de no transformar en arbitrario su proceder. No coincidimos, por ende, con aquellas posturas jurisprudenciales que propugnan que el juicio de proporcionalidad se encontraría "ya realizado por el legislador de un modo abstracto y general, al haber ejercido previamente la opción valorativa, vinculante para el juez, de preferir la eficiencia de los procesos judiciales por sobre la libertad de los ciudadanos, sean estos imputados, víctimas, testigos o peritos". ${ }^{22}$ Ello, pues, como bien lo ha sostenido el Comité de Derechos Humanos de las Naciones Unidas:

"las medidas restrictivas deben ajustarse al principio de proporcionalidad; deben ser adecuadas para desempeñar su función protectora; deben ser el instrumento menos perturbador de los que permitan conseguir el resultado deseado, y deben guardar proporción con el interés que debe protegerse. El principio de proporcionalidad debe

\footnotetext{
${ }^{21}$ Tribunal Constitucional de Chile, sentencia causa rol $\mathrm{n}^{\circ}$ 2744-2014, de 8 de octubre de 2015, considerando vigésimo segundo, pp. 30-31. Sobre el tratamiento del principio de proporcionalidad en la jurisprudencia constitucional chilena. Cfr. NAVARRO BELTRÁN, Enrique, "Notas sobre el Principio de Proporcionalidad en la reciente jurisprudencia constitucional", Revista de Derecho Público n/e (2018), pp. 309-322, passim; COVARRUBIAS CUEVAS, Ignacio, “¿Emplea el Tribunal Constitucional el test de proporcionalidad? (128 sentencias del tribunal constitucional en la perspectiva de la jurisprudencia constitucional alemana, de la cámara de los lores y del tribunal europeo de derechos humanos)", Estudios Constitucionales $\mathrm{n}^{\circ} 12$ (2014) 1, pp. 163-237, passim; ARNOLD, Rainer; MARTÍNEZ ESTAY, José Ignacio; ZÚÑIGA URBINA, Francisco, "El principio de proporcionalidad en la jurisprudencia del Tribunal Constitucional", Estudios Constitucionales $\mathrm{n}^{\circ} 10$ (2012) 1, pp. 65-115, passim.

${ }^{22}$ Corte Suprema de Justicia de Chile, sentencia causa rol $\mathrm{n}^{\circ}$ 5044-2009, de 4 de agosto de 2009, considerando séptimo.
} 


\section{Polít. Crim. Vol. 14, № 28 (Diciembre 2019), Art. 4, pp. 152-185. [http://politcrim.com/wp-content/uploads/2019/10/Vol14N28A4.pdf]}

respetarse no solo en la ley que defina las restricciones sino también por las autoridades administrativas y judiciales que la apliquen". ${ }^{23}$

Es a la luz de los desarrollos expuestos, por lo tanto, que debiesen también analizarse todas las condiciones -necesarias y suficientes- para validar los denominados hallazgos casuales en el proceso penal y, de este modo, considerar su eventual aplicabilidad a la luz de una base metodológica idónea para articular su concreto proceder práctico.

\section{Los hallazgos casuales: nociones conceptuales y manifestaciones en el Derecho comparado}

Durante la realización de una diligencia de intervención telefónica o una entrada y registro a un domicilio, a propósito de la investigación de un hecho punible, los operarios encargados de llevarla a cabo pueden recabar antecedentes útiles para la investigación. Ese es el objetivo de la medida. Sin embargo, es frecuente que, durante la ejecución de una legítima intervención telefónica o un allanamiento, autorizados por el juez de garantía, se tome conocimiento de datos o informaciones, o bien, se encuentran objetos o documentos relacionados con un delito distinto del que había sido objeto de la medida. ${ }^{24}$ Es decir, podría llegarse a conocer acerca de hechos nuevos relativos a otro delito, ya sea conexo o inconexo con el objeto de la investigación actual, y que pueden afectar al imputado y/o a terceras personas no imputadas en el procedimiento, sean o no titulares de los equipos telefónicos intervenidos, ${ }^{25}$ por ejemplo.

Según hemos podido advertir, los hallazgos casuales o fortuitos se presentan siempre que se descubran de forma sorpresiva e inesperada, en el marco de la ejecución de una medida restrictiva de derechos judicialmente decretada, evidencias que demuestran la existencia de un hecho punible diverso del que en principio se estaba investigando. De ahí que sea posible conceptualizar dicho instituto de modo diverso, dependiendo precisamente del énfasis que se quiera dar a alguno de sus factores. En efecto, para algunos el problema de los hallazgos casuales se constataría “(...) cuando se obtienen resultados probatorios derivados de la realización de determinadas diligencias encaminadas en un principio a la investigación de un determinado delito distinto o afectando a un tercero no inicialmente investigado". ${ }^{26}$ Para otros, en cambio, los hallazgos casuales involucrarían “(...) los conocimientos adquiridos mediante una intervención telefónica legítimamente ordenada y ejecutada que no se corresponden con el fin inmediato de la investigación penal para la que

\footnotetext{
${ }^{23}$ Comité de Derechos Humanos de Naciones Unidas, Observación General No 34, de 21 de julio de 2011, sobre "El Derecho a la Libertad de Opinión y de Expresión Garantizado en el Artículo 19 del Pacto Internacional de Derechos Civiles y Políticos", párrafo 34.

${ }^{24}$ GARCÍA, Luis M., "La vigilancia de las telecomunicaciones y otras comunicaciones interpersonales según la jurisprudencia elaborada en torno al Código Procesal Penal de la Nación", en: HAZAN, Luciano A; PLAZAS, Florencia G. (coords.), Garantías constitucionales en la investigación penal: un estudio crítico de la jurisprudencia, Buenos Aires: Editores del Puerto, 2006, pp. 308-358, p. 354.

${ }_{25}$ ALONSO PÉREZ, Francisco, Intervención de las comunicaciones postales, telegráficas y telefónicas. Legislación, comentarios, jurisprudencia, Madrid: Dykinson, 2001, p. 123.

${ }^{26}$ ÁLVAREZ DE NEYRA KAPPLER, Susana, "Los descubrimientos casuales en el marco de una investigación penal (con especial referencia a las diligencias de entrada y registro en domicilio)", Revista internacional de estudios de Derecho Procesal y Arbitraje n 2 (2011), pp. 1-69, p. 4.
} 
se autoriza dicha medida, y/o que afectan -o provienen- de personas frente a las cuales no se ha ordenado dicha intervención o que no hubiera podido ordenarse frente a ellas según los presupuestos normativos objetivos y subjetivos". ${ }^{27}$

Ahora bien, aunque esta última conceptualización se centra en la medida intrusiva de interceptación de las comunicaciones, ${ }^{28}$ lo cierto es que ambas definiciones presentan ciertas vaguedades e imprecisiones que es preciso poner de relieve. En primer término, porque no es posible sostener que los supuestos de procedencia de la institución se den sólo y exclusivamente para ciertas diligencias intrusivas. De hecho, si bien lo normal es que ello se explique porque son precisamente a propósito de las dos medidas -incautación e interceptación de las comunicaciones- que el legislador ha establecido una regulación positiva de la institución en comento (por ejemplo, en Chile), ello no implica que pueda presentarse la posibilidad de aplicar los hallazgos casuales respecto de otras medidas intrusivas. ${ }^{29}$ De este modo, los llamados hallazgos casuales operan siempre que exista una medida restrictiva de derechos fundamentales judicialmente decretada, cualquiera sea su concreta naturaleza y manifestación particular.

En segundo lugar, tampoco parece correcto que las definiciones hagan referencia al descubrimiento como "simples conocimientos adquiridos" o "meros resultados probatorios", en especial si se considera que el elemento básico en el hallazgo casual no puede ser tan vago. ${ }^{30}$ De hecho, aunque las soluciones que ofrecen la doctrina y la jurisprudencia en este sentido no son necesariamente unívocas, si están de acuerdo en enfatizar que los nuevos antecedentes deben demostrar la existencia de un delito diverso al inicialmente investigado y la participación culpable del imputado en el mismo. De ahí que cada vez que aparezcan nuevos hechos o indicios en la práctica de cualquier medida intrusiva restrictiva de derechos fundamentales, tales antecedentes deban tener el mérito e intensidad suficientes para determinar el carácter punible del nuevo hecho.

27 LÓPEZ-FRAGOSO, Tomás, "Los descubrimientos casuales en las intervenciones telefónicas como medidas coercitivas en el proceso penal", Derecho y libertades: Revista del Instituto Bartolome de las Casas n'2 (1993-1994), pp. 81-90, pp. 82-83.

${ }^{28}$ En otras palabras, puede ocurrir, por ejemplo, que al intervenir judicialmente una comunicación quede patente en ella la comisión de un delito distinto del que motivó la investigación, o que, tras entrar en un domicilio con autorización judicial específica para investigar un determinado delito, aparezcan fuentes de prueba relativas a otros distintos, etc. Estamos ante el problema de los descubrimientos casuales, que presuponen la existencia de una intervención autorizada, DÍAZ CABIALE, José Antonio; MARTÍN MORALES, Ricardo, La garantía constitucional de la admisión de la prueba ilícitamente obtenida, Madrid: Civitas, 2001, p. 177. También consultar: MONTERO AROCA, Juan, La intervención de la comunicaciones telefónicas en el proceso penal, Valencia: Tirant lo Blanch, 1999, pp. 188 y ss,; RODRÍGUEZ SOL, Luis, Registro domiciliario y prueba ilícita, Granada: Comares, 1998, pp. 232 y ss., y, GUTIÉRREZ ZARZA, Ángeles, Investigación y enjuiciamiento de los delitos económicos, Madrid: Colex, 2000, pp. 273 y ss..

${ }^{29}$ Por ejemplo, ello podría ocurrir en un examen corporal para investigar un delito de lesiones, para lo cual se practican radiografías al sujeto, las que sin quererlo, dan cuenta de que aquel lleva en el interior de su cuerpo un ovoide con drogas, FUENTES PRINCE, Sebastián, Hallazgo casual de evidencia con ocasión de la práctica de diligencias intrusivas en el marco del proceso penal, Memoria de Prueba, Pontificia Universidad Católica de Valparaíso, Valparaíso, 2015, p. 6.

${ }^{30}$ FUENTES PRICE, Sebastián, Hallazgo, cit. nota n²9, p. 6. 


\section{Polít. Crim. Vol. 14, No 28 (Diciembre 2019), Art. 4, pp. 152-185. [http://politcrim.com/wp-content/uploads/2019/10/Vol14N28A4.pdf]}

En tercer lugar, se debe resaltar que los hallazgos casuales tampoco se verifican única y exclusivamente a partir del descubrimiento fortuito de "nuevos hechos delictuales", pues, producto de la ejecución medida coercitiva respectiva, pueden aparecer también nuevos antecedentes que demuestren la participación de otros imputados distintos de los inicialmente investigados. Por consiguiente, dos son los posibles escenarios en los cuales pueden manifestarse los hallazgos casuales: por un lado, cuando se afecte el ámbito objetivo de la investigación, en el sentido de aparecer nuevos hechos que demuestren la existencia de un delito diverso al investigado; y por otro lado, cuando se afecte el ámbito subjetivo de la investigación, vale decir, cuando se descubran nuevos antecedentes que demuestran la participación criminal de sujetos distintos de los inicialmente investigados.

Respecto a la ocurrencia de estos hallazgos, tenemos que indicar que los descubrimientos fortuitos se producen, en la praxis, no por razones jurídicas, sino por razones técnicas, propias de la ejecución de la medida intrusiva. Su casualidad viene dada por la ausencia de previsibilidad, pues es en el momento en que se realiza la interceptación o la entrada y registro cuando éstos tienen lugar. Desde una perspectiva jurídica, ha de considerarse que el fin perseguido por una vigilancia telefónica descansa en la obtención de antecedentes o la comprobación de hechos importantes para el proceso, aun cuando se refieran a personas distintas al imputado. ${ }^{31}$ Estos terceros constituirían los intermediarios, es decir, el sujeto ajeno ha de participar en la conversación que tiene con el imputado. Por su parte, en el caso de una diligencia de entrada y registro y posterior incautación, el fin descansa en la obtención de evidencias que sean útiles para la investigación que se lleva a cabo.

Por último, y al alero de lo reseñado, se debe destacar que los hallazgos casuales siempre denotan una ruptura con el principio de especialidad, vale decir, aquel en cuya virtud se habilita la restricción de algún derecho fundamental con el único fin de permitir de obtención de una fuente de prueba concreta y específica señalada por la orden jurisdiccional que habilita la injerencia estatal. De esta forma, si bien el sistema procesal penal impide conceder autorizaciones genéricas para la búsqueda de antecedentes que demuestren posibles infracciones penales, los hallazgos casuales constituye su más clara excepción y, por consiguiente, no se encuentran cubiertos por la resolución judicial que previamente autorizó la ejecución de la medida intrusiva o coercitiva de derechos.

Sentado lo anterior, se hace preciso señalar que la consagración normativa de los hallazgos casuales presentan diversas manifestaciones en el Derecho comparado. De hecho, mientras en algunos países de nuestro sistema europeo-continental ha sido el propio legislador quien se ha encargado de fijar reglas específicas sobre el particular, en otros -a falta de norma expresa- ha sido la jurisprudencia la que ha delimitado el campo de aplicación de la figura en estudio. ${ }^{32}$ El problema a resolver, sin embargo, tanto en uno como en otro caso, siempre presenta un mismo denominador común: dilucidar si es posible o no utilizar los

\footnotetext{
${ }^{31}$ LÓPEZ-FRAGOSO ÁLVAREZ, Tomás, Las intervenciones telefónicas en el proceso penal, Madrid: Colex, 1991, p. 68.

${ }^{32}$ Como señala Tapia, en la legislación penal federal de Argentina no se encuentra regulada por el legislador TAPIA, Juan Francisco, "Descubrimientos accidentales en el curso de un registro domiciliario o una interceptación de comunicaciones. El problema de los hallazgos casuales ¿o causales?”, Pensamiento penal, $\mathrm{n}^{\circ} 85$ (2009), p. 2, en: http//pensamientopenal.com.ar [visitado el 10.07.2018]).
} 
antecedentes fácticos descubiertos de forma casual en la ejecución de una medida coercitiva $\mathrm{y}$, en su caso, determinar si tales antecedentes adolecen o no de una posible ilicitud.

En Alemania, por ejemplo, el legislador se ha encargado de regular en diversos parráfos de de la Ordenanza Procesal Penal (StPO) los hallazgos casuales -"Zufallsfunde"- obtenidos a partir de un registro domiciliario, un agente encubierto, o bien una intervención de comunicaciones, siempre que cualquiera de dichas medidas hayan sido ordenadas y ejecutadas legítimamente. ${ }^{33}$ Para ello, no obstante, es menester que concurran ciertos requisitos copulativos: en primer lugar, que los conocimientos hayan sido adquiridos efectivamente de forma inesperada y fortuita, esto es, no buscados "ex profeso" o de forma provocada a partir de una ejecución de una medida coercitiva. ${ }^{34}$ En segundo lugar, que se trate de descubrimientos casuales relativos a algún hecho delictivo de los expresamente catalogados en el $\S 100$ a de la StPO, vale decir, delitos de especial gravedad tipificados en los diversos cuerpos normativos a que dicho parágrafo se refiere. ${ }^{35}$ En tercer lugar, que a partir de la ejecución de la medida coercitiva de que se trate, aparezcan antecedentes que revelen la sospecha fundada de que la persona investigada u otra diversa ha cometido - $\mathrm{o}$ intentado cometer- un hecho punible comprendido en el catálogo, pero no cubierto por la resolución judicial que autoriza la medida coercitiva. ${ }^{36} \mathrm{Y}$, por último, según lo dispone el $\S$ $477, \mathrm{~N}^{\mathrm{o}} 2$, parte segunda, que los datos o antecedentes obtenidos a partir de la ejecución de la medida coercitiva "puedan ser utilizados en otros procedimientos sólo para el esclarecimiento de aquellos delitos para cuya determinación hubiera podido ser ordenada tal medida de acuerdo con la ley". ${ }^{37-38}$

${ }^{33}$ Cfr. ROXIN, Claus; SCHÜNEMANN, Bern, Strafverfahrensrecht, CH. Beck, München, 2010, pp. 286 y ss.; y BEULKE, Werner, Strafprozessrecht, Heidelberg: CF. Müller, 2012, pp. 178 y ss. Sobre el tema de prohibición de producción de prueba y prohibición de valoración en el campo penal, consultar, entre otros: JÄGER, Christian, Beweisverwertung und Beweisverwertungsverbote um Strafprozess, CH. Beck, München, 2002, passim, y, AMBOS, Kai, Beweisverwertungsverbote.: Grundlagen und Kasuistik - internationale Bezüge - ausgewählte Probleme, Duncker und Humblot: Berlin, 2010, passim. Para una mirada de la regla de la exclusión en Chile desde Alemania ver: CORREA, Carlos, "Más allá de la regla de exclusión: prohibiciones probatorias en el Derecho chileno", Política Criminal, Vol. 13, n 25 (2018), pp. 144-174, passim.

34 Así, como certeramente expresa Volk: "La causalidad y la intensionalidad se excluyen entre sí. Es inadmisible, pues, buscar deliberadamente objetos a los cuales la orden no se refieren, o utilizar la orden como mero pretexto para una busqueda semejante". VOLK, Klaus, Curso fundamental de Derecho procesal penal, Trads.: NANZER, Alberto; NÚÑEZ, Noelia; PASTOR, Daniel; SARRABAYROUSE, Eugenio, Buenos Aires: Hamurabi, 2016, p. 142.

${ }^{35}$ De este forma, como plantea el profesor Ambos, "una utilización es inadmisible para la averiguación sobre hechos delictivos no comprendidos en el catálogo del $\S 100 \mathrm{a}$ y, por supuesto, también es inadmisible en caso de que la medida de antemano sea materialmente ilegal"; AMBOS, Kai, "Las prohibiciones de utilización de prueba en el proceso penal alemán - Fundamentación teórica y sistematización, Política Criminal nº7 (2009), pp. 1-51, p. 19.

${ }^{36}$ Esto pues, por aplicación supletoria del $\S 100 \mathrm{a}$, se exigen: "bestimmte Tatsachen den Verdacht begründen, dass jemand als Täter oder Teilnehmer eine in Absatz 2 bezeichnete schwere Straftat begangen, in Fällen, in denen der Versuch strafbar ist, zu begehen versucht, oder durch eine Straftat vorbereitet" ["ciertos hechos que fundamenten la sospecha de que alguien, como autor del delito o participe, ha cometido o, en casos en los que la tentativa es punible, ha intentado cometer, o ha preparado mediante un delito"].

37 "Ist eine Maßnahme nach diesem Gesetz nur bei Verdacht bestimmter Straftaten zulässig, so dürfen die auf Grund einer solchen Maßnahme erlangten personenbezogenen Daten ohne Einwilligung der von der Maßnahme betroffenen Personen zu Beweiszwecken in anderen Strafverfahren nur zur Aufklärung solcher 


\section{Polít. Crim. Vol. 14, № 28 (Diciembre 2019), Art. 4, pp. 152-185. [http://politcrim.com/wp-content/uploads/2019/10/Vol14N28A4.pdf]}

En Italia, por otro lado, se debe observar que el hallazgo casual -"scoperta casuale"- no tiene una regulación general en el Codice di Procedura Penale (CPPI) del año 1988. En efecto, con la entrada en vigencia de dicho Código si bien se reguló una prohibición de valoración de las pruebas obtenidas en violación de las prohibiciones establecidas en la ley -a través de la llamada "inutilizzabilità"-, el legislador no reconoció específicamente cómo y de qué forma se debía hacer frente a los descubrimientos casuales derivados de la ejecución de alguna medida coercitiva. Antes bien, sólo enfatizó en su artículo $270 \mathrm{~N}^{\circ} 1$ que "los resultados de las interceptaciones [de conversaciones o comunicaciones] no pueden ser utilizados en procedimientos diversos de aquél en el que han sido dispuestos, salvo que resulten indispensables para la averiguación de delitos por los cuales es obligatorio en arresto en flagrancia". A partir de ello, han sido la propia doctrina y la jurisprudencia quienes se han encargado de delinear la "scoperta casuale" con un ámbito de aplicación más general: por un lado, reconociendo que si durante la práctica de cualquier diligencia coercitiva se descubren nuevos antecedentes que permitieren sospechar la existencia de un hecho punible distinto del investigado, las nuevas fuentes de prueba no podrían -en principio- hacerse valer en dicho procedimiento, dada la falta de una concreta resolución judicial que las haya autorizado, ponderado y motivado $;{ }^{39} \mathrm{y}$, por otro lado, que dicha forma de "inutilizzabilità speciale" ${ }^{40}$ no excluye, en todo caso, que el contenido de las fuentes de prueba descubiertas de forma casual puedan hacerse valer como "notitia criminis" en otro procedimiento, en especial si tienen cierta intensidad y se verifican en situación de flagrancia. ${ }^{41}$ En consecuencia, en el Derecho Italiano, sobre la base de la

Straftaten verwendet werden, zu deren Aufklärung eine solche Maßnahme nach diesem Gesetz hätte angeordnet werden dürfen".

${ }^{38}$ También se debe tener presente que la Ordenanza Procesal Penal alemana dispone que respecto de los datos de una vigilancia acústica (el $\S 100 d$ ap. 5 de la StPO) podrán utilizarse para otros fines bajo ciertas condiciones, a saber: 1) Que los datos obtenidos a través de la medida del el § 100c podrán ser aprovechados en otros procesos penales sin consentimiento de las personas vigiladas para el esclarecimiento de un delito respecto de los cuales procedería dicha medida de conformidad al $§ 100 \mathrm{c}$, o para la averiguación del paradero de una persona acusada de tal delito; 2) Que los datos referidos a personas obtenidos a través de la medida del el $\S 100$ c con el fin de evitar un peligro, sólo están autorizados para la evitación de un peligro para la vida existente en el caso concreto o de un peligro urgente para el cuerpo o la liberta de una persona u objetos significativamente valiosos que sirven al abastecimiento de la población, que son de destacado valor culturar en el parágrafo 305 del Código Penal alemán. Los datos utilizables y referidos a la persona, obtenidos, obtenidos a través de una medida en virtud del § 100c también podrán ser empleados para evitar un peligro existente, urgente en el caso concreto, que amenace otros bienes patrimoniales significativos. Si los datos dejan de ser necesarios para la evitación del peligro o para la inspección prejudicial o judicial de la medida tomada para evitarlo, las grabaciones deberán ser borradas de inmediato por la autoridad responsable de la evitación del peligro. En la media que el borrado se postergue simplemente para una eventual inspección prejudicial o judicial, los datos sólo podrá ser utilizados para ese fin; y 3) Si los datos utilizables referidos a la persona son obtenidos a través de una medida propia del derecho de policías, podrán ser empleados en un proceso penal sin consentimiento de la persona vigilada sólo para el esclarecimiento de un delito en virtud del cual la medida del § 100c podría ser ordenada, o para la averiguación del paradero de la persona acusada del tal delito.

39 En argumento, Cfr. CHIAVARIO, Mario, Diritto Processuale Penale. Profilo instituzionale, Torino: UTET, 2012, pp. 421 y ss.. y DOMINIONI, Oreste, et al, Procedura penale, Torino: Giappicheli, 2010, p. 226; CAMON, Alberto, Le intercettazione nel proceso penal, Milano: Guiffrè Editore, 1996, pp. 199 y ss. .

${ }^{40}$ Cfr. TONINI, Paolo, Manuale di Procedura Penale, Milano: Giuffrè Editore, 2012, p. 201.

${ }^{41}$ En materia de interceptaciones telefónicas y comunicaciones informáticas o telemáticas, huelga destacar que la Ley $\mathrm{n}^{\mathrm{o}}$ 9, de 14 de enero de 2013, introdujo en el artículo 266 del CPPI una nueva letra f), en cuya 
norma recién trascrita, se resuelve indirectamente el problema de los hallazgos casuales, admitiendo excepcionalmente la utilización de los resultados obtenidos en la ejecución de una medida coercitiva, siempre y cuando las nuevas fuentes de prueba demuestren la existencia de un delito particularmente grave que amerite una detención en flagrancia. ${ }^{42}$

En España, por último, la Ley Orgánica $n^{\circ} 13 / 2015$, de 5 de octubre de $2015,{ }^{43}$ que modificó la Ley de Enjuiciamiento Criminal -(en adelante, LECrim)- para el fortalecimiento de las garantías procesales y la regulación de las medidas de investigación tecnológica, ${ }^{44}$ creó un nuevo artículo 579 bis $^{45}$ el cual estatuye dos reglas basales en materia de hallazgo casual: por una parte, que el resultado de pruebas obtenidas en la ejecución de una medida coercitiva podrá ser utilizado como medio de investigación o prueba en otro proceso penal; y, por otra, que "la investigación del delito casualmente descubierto requiere autorización del juez competente, para la cual, éste comprobará la diligencia de la actuación, evaluando el marco en el que se produjo el hallazgo casual y la imposibilidad de haber solicitado la medida que lo incluyera en su momento" (art. 579 bis, $\mathrm{N}^{\mathrm{o}}$ 3, LECrim). De ahí que, para los efectos de tal prescripción, el material probatorio obtenido casualmente y ajeno al objeto de la investigación sea completamente válido, siempre y cuando tal circunstancia sea puesta inmediatamente en conocimiento del juez competente, y éste, a su vez, resuelva de forma motivada cualquiera de estas dos medidas: o la ampliación de la investigación al ilícito casualmente descubierto, o el inicio de una

virtud, a la posibilidad de investigar cierta clase de delitos por esta vía, se agregan otras figuras delictivas de gravedad, tales como: el tráfico ilícito de estupefacientes y sustancias psicotrópicas, el contrabando de armas y explosivos, la distribución y divulgación por vía telemática de material pornográfico infantil, etc. Para una visión crítica al respecto, Cfr. SPANGER, Giorgio, "Le criticità della disciplina delle intercettazioni telefoniche", Diritto Penale e Processo, n7 (2016), pp. 921 y ss.

${ }^{42}$ Esto, claro está, sólo siempre y cuando el nuevo delito no tenga nexo o conexión alguna con el inicialmente investigado. Ello porque, como ha señalado la Corte de Casación Italiana: "l'individuazione della vera e profonda ratio del divieto ex articolo 270 codice di procedura penale, derogabile solo fronte dell'indispensabilità per accertare i più gravi delitti legittimanti l'arresto obbligatorio in flagranza, consente di conferire, secondo il tribunale del riesame, maggiore concretezza alle astratte e difficilmente decodificabili categorizzazioni giurisprudenziali relative alle produzioni di "stesso procedimento sostanziale", o di "nesso oggettivo, soggettivo, probatorio, finalistico" dei fatti, o di "autorizzazione in bianco" sottraendole ad interpretazioni equivoche e relativistiche". Corte de Casación Italiana. Sesión III, de 30 de julio de 2015, N 33.598. De este modo, "in tema di intercettazione di conversazioni, ai fini del divieto di utilizzazione previsto dall'articolo 270, comma primo, cod. proc. pen., nel concetto di "diverso procedimento" non rientrano le indagini strettamente connesse e collegate sotto il profilo oggettivo, probatorio e finalistico al reato alla cui definizione il mezzo di ricerca della prova viene predisposto, né tale nozione equivale a quella di "diverso reato", sicché la diversità del procedimento deve essere intesa in senso sostanziale, non collegabile al dato puramente formale del numero di iscrizione nel registro delle notizie di reato". Corte de Casación Italiana, Sesión III, de 18 de diciembre de 2014, $\mathrm{n}^{\circ} 52.503$.

${ }^{43}$ Ver: ARMENTA DEU, Teresa, Lecciones de Derecho procesal penal, Madrid: Marcial Pons, 2017, pp. 194 y ss.; y NIEVA FENOLL, Jordi, Derecho Procesal III. Proceso penal, Madrid: Marcial Pons, 2017, passim.

${ }^{44}$ Sobre esta reforma, Cfr. GONZÁLEZ-MONTES SÁNCHEZ, José Luis, "Reflexiones sobre el proyecto de Ley Orgánica de modificación de la LECrim para el fortalecimiento de las garantías procesales y la regulación de las medidas de investigación tecnológicas", RECPC n¹7-06 (2015), pp. 1-41, passim.

${ }^{45}$ Sobre el origen de esta norma, se puede evidenciar un sostenido caudal jurisprudencial que se pronunciaba

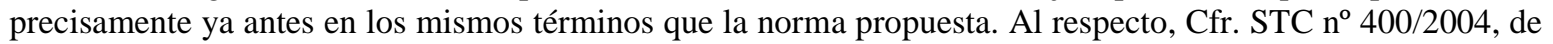
27 de octubre, foja 2; SSTS n $740 / 2012$, de 10 de octubre, no 818/2011, de 21 de julio, y no 372/2010, de 29 de abril. 


\section{Polít. Crim. Vol. 14, No 28 (Diciembre 2019), Art. 4, pp. 152-185. [http://politcrim.com/wp-content/uploads/2019/10/Vol14N28A4.pdf]}

investigación absolutamente independiente. Ello dependerá, según lo dispone el artículo 17, $\mathrm{N}^{\mathrm{o}}$ 1, de la LECrim, si los nuevos antecedentes constitutivos de delito son o no conexos, vale decir, si existe una relación objetiva y subjetiva entre el hecho punible nuevo y el originalmente investigado. En consecuencia, si los hechos descubiertos tienen una conexión con los que son objeto del procedimiento instructorio, tales hallazgos surtirán efectos tanto de investigación cuanto de prueba; por el contrario, si los hechos ocasionalmente descubiertos no guardan esa conexión, se estimarán como mera "notitia criminis" y deberán ser puestos en conocimiento de la autoridad competente para que se inicie el correspondiente procedimiento. ${ }^{46}$

\section{Los hallazgos casuales en Chile y sus manifestaciones jurisprudenciales}

Con la entrada en vigencia del actual sistema procesal penal, nuestro legislador reguló expresamente los hallazgos casuales a propósito de dos medidas coercitivas particulares: por un lado, la entrada y registro originadas en una orden judicial previa; y, por otro lado, la interceptación de las comunicaciones telefónicas.

En efecto, tratándose de la diligencia de entrada y registro, su regulación se encuentra en el artículo 215 del Código Procesal Penal. ${ }^{47}$ En efecto, se trata de una norma que fue recientemente modificada por la Ley $\mathrm{N}^{\circ} 20.931$, de 5 de julio de 2016, que facilita la aplicación efectiva de las penas establecidas para los delitos de robo, hurto y receptación y mejora la persecución penal en dichos delitos, puesto que hasta antes de la referida reforma los funcionarios policiales sólo podían proceder a la incautación de objetos y documentos descubiertos casualmente "previa orden judicial" ${ }^{48}$ Dentro de las razones que se

\footnotetext{
${ }^{46}$ Respecto de este último supuesto, se debe destacar la STS no 249/2016, de 19 de mayo de 2016, la cual expresa: “(...) en estos supuestos en que se investiga un delito concreto y se descubre otro distinto, no puede renunciarse a investigar la notitia criminis incidentalmente descubierta en una intervención dirigida a otro fin, aunque ello pueda hacer precisa una nueva o específica autorización judicial o una investigación diferente de la del punto de arranque. Otra cosa significaría por ejemplo, la impunidad de un grave asesinato que se descubriera en un domicilio registrado o en una intervención telefónica acordada para descubrir estupefacientes para el tráfico o acreditar productos de receptación”. En idéntico sentido, Cfr. STS $\mathrm{n}^{\circ} 291 / 2013$, de 14 de marzo.

47 " Objetos y documentos no relacionados con el hecho investigado. Si durante la práctica de la diligencia de registro se descubriere objetos o documentos que permitieren sospechar la existencia de un hecho punible distinto del que constituyere la materia del procedimiento en que la orden respectiva se hubiere librado, podrán proceder a su incautación, debiendo dar aviso de inmediato al fiscal, quien los conservará".

${ }^{48}$ En efecto, la norma en comento señalaba: "Si durante la práctica de la diligencia de registro se descubren objetos o documentos que permitieren sospechar la existencia de un hecho punible distinto del que constituyere la materia del procedimiento en que la orden respectiva se hubiere liberado, podrán proceder a su incautación previa orden judicial". Huelga destacar, en todo caso, que el texto original de dicha norma propuesto por el Ejecutivo era el siguiente: "Si durante la práctica de la diligencia de registro el ministerio público o la policía descubrieren objetos o documentos que permitieren sospechar la existencia de un hecho punible distinto del que constituya la materia del procedimiento en que la orden respectiva se hubiere librado, podrán proceder a su incautación en forma provisional. Dichos objetos o documentos serán conservados por el ministerio público. En estos casos deberá obtenerse el pronunciamiento judicial de que trata el artículo 282 inciso tercer". Sin perjuicio de ello, dicho artículo fue aprobado en la Cámara de Diputados, en lo que nos interesa en este punto, con una importante enmienda: se dejó establecido que todo esto debe hacerse con aprobación judicial previa, para lo cual se sustituyó la frase "en forma provisional" por la oración "previa orden judicial" y se eliminó el párrafo final: en estos casos deberá obtenerse el pronunciamiento judicial de
} 
esgrimieron para impulsar tal modificación, se señaló que "la demora en obtener dicha autorización judicial puede provocar que determinados medios de comprobación del delito o de la participación de personas determinadas en él se malogren, razón por la cual y siguiendo el criterio de "causa probable", dicha situación debiera ser considerada como un antecedente razonable que permita proceder a la incautación en forma inmediata, sin perjuicio del derecho del imputado o de terceros ajenos al procedimiento de recurrir al juez de garantía, en conformidad a las reglas generales". "De ahí que, dado que no existirían mayores razones para diferenciar los elementos descubiertos casualmente en una diligencia de entrada y registro y los aspectos que rodean una situación de flagrancia, ${ }^{50}$ se haya decidido modificar el artículo 215 del CPP remplazando la frase "podrán proceder a su incautación previa orden judicial" por "podrán proceder a su incautación debiendo dar aviso de inmediato al fiscal, quien los conservará". De esta forma, no obstante la clara inspiración iusfundamental que motivó la redacción primigenia del referido artículo 215 del CPP ${ }^{51}$ y que exigía contar con una resolución judicial motivada en caso actuaciones de investigación potencialmente lesivas de derechos fundamentales, hoy día se permita en nuestro medio la incautación casi automática de ciertas fuentes de prueba descubiertas casualmente en la ejecución de la medida entrada y registro. En otros términos, autorizada judicialmente una entrada y registro en lugar cerrado, la policía "puede" recoger e incautar todos aquellos objetos o documentos que resulten relevantes para la investigación de un delito diverso al investigado, siempre y cuando se dé aviso inmediato de dicha circunstancia al fiscal.

que trata el artículo 282 inciso tercero. Sobre el particular, Cfr. Historia de la Ley No 19.696 que establece el Código Procesal Penal, pp. 1404 y ss.

${ }^{49}$ Informe de la Comisión de Seguridad Ciudadana recaído en el Proyecto de Ley que facilita la aplicación efectiva de las penas establecidas para los delitos de robo, hurto y receptación y mejora la persecución penal en dichos delitos: boletín 9885-07. Sesión nº 43, de 2 de julio de 2015, p. 46.

${ }^{50}$ Así, a juicio del diputado Squella, "debería eliminarse este requisito [de la orden judicial previa], ya que no hay razón para hacer la diferencia respecto de elementos encontrados en una diligencia o en una actuación ante flagrancia”. Informe de la Comisión de Constitución, Legislación, Justicia y Reglamento de la Camara de Diputados recaído en el Proyecto de Ley que facilita la aplicación efectiva de las penas establecidas para los delitos de robo, hurto y receptación y mejora la persecución penal en dichos delitos: boletin n ${ }^{\circ}$ 9885-07-1. Sesión 66, de 03 de septiembre de 2015, pp. 74-75.

${ }^{51}$ Sin perjuicio de ello, huelga destacar que para la redacción de dicha norma se tomó en cuenta el parágrafo 108 de la StPO, el cual sostiene: "Beschlagnahme anderer Gegenstände: (1) Werden bei Gelegenheit einer Durchsuchung Gegenstände gefunden, die zwar in keiner Beziehung zu der Untersuchung stehen, aber auf die Verübung einer anderen Straftat hindeuten, so sind sie einstweilen in Beschlag zu ehmen. Der Staatsanwaltschaft ist hiervon Kenntnis zu geben. Satz 1 findet keine Anwendung,soweit eine Durchsuchung nach $\S 103$ Abs. 1 Satz 2 stattfindet" ["Confiscación de otros objetos: Si con ocasión de un registro se encuentran objetos que no guardan ninguna relación con la investigación, pero aluden a la perpetración de otro delito, deberán de inmediato ser confiscados. A la fiscalía se le deberá informar de ello. No se aplicará el inciso $1^{\circ}$, siempre que tenga lugar el registro según $\S 103$, apartado $1^{\circ}$, inciso $\left.2 "\right]$. No obstante ello, conviene recalcar que también dentro de la inspiración de dicha norma se tomó el artículo 182 del Código de Procedimiento Penal Chileno de 1906, el cual señalaba: "Si durante la pesquisa de que se trata en el presente párrafo, se descubrieren objetos o datos que permitan sospechar la existencia de un delito distinto del que es materia del sumario y del cual nazca acción pública, el juez, si tuviere competencia para el juzgamiento del nuevo delito, extenderá a él sus investigaciones, formando o no proceso separado según las reglas legales; pero si careciere de competencia, se limitará a recoger los datos u objetos encontrados y a ponerlos a disposición del juez correspondiente con una relación de los antecedentes del caso"]. 


\section{Polít. Crim. Vol. 14, No 28 (Diciembre 2019), Art. 4, pp. 152-185. [http://politcrim.com/wp-content/uploads/2019/10/Vol14N28A4.pdf]}

Por otro lado, tratándose de interceptaciones en las comunicaciones telefónicas, el artículo 223 inciso $4^{\circ}$ del CPP fija también directrices sobre los hallazgos casuales y el destino de las comunicaciones no relacionadas con el hecho investigado. En efecto, dado que las interceptaciones sobre una línea telefónica no puede significar privar o restringir la vida privada o la intimidad "ad nütum" del sujeto investigado, la norma en comento deja claro que las comunicaciones que fuesen irrelevantes para el procedimiento deben ser entregadas, en su oportunidad, a las personas afectadas con la medida y, acto seguido, se debe destruir toda transcripción o copia de ellas por parte del ministerio público. ${ }^{52}$ Sin perjuicio de ello, el inciso final de la misma disposición establece una importante excepción a partir del problema de los hallazgos casuales. En efecto, la regla especial consiste en que las informaciones provenientes de grabaciones telefónicas que sean "per se" irrelevantes en el procedimiento en el cual fueron autorizadas, no sean eliminadas, en la medida que puedan contener "(...) información relevante para otros procedimientos seguidos por hechos que pudieren constituir un delito que merezca pena de crimen”. De ahí que no todo material recopilado por esta vía deba ser destruido, pues, si el descubrimiento se refiere a hechos delictivos para los cuales la ley establece una pena igual o superior a cinco años de privación de libertad, la nueva fuente de prueba deberá conservarse. En otras palabras, nuestro legislador se preocupó de señalar expresamente el requisito relacionado con la gravedad del delito imputado, de manera que cualquier antecedente relativo a un hecho punible de menor gravedad desde la perspectiva de su penalidad abstracta, no podría ser utilizado y deberá ser destruido, siguiendo la regla general del artículo 223 inciso $4^{\circ}$ del Código Procesal Penal.

En esta orden de ideas, Marcazzolo reconoce dos hipótesis de hallazgo casual en la norma transcrita: la primera consiste en que de la interceptación de un número telefónico aparezcan informaciones relevantes para otros hechos que pueden ser sancionados con pena de crimen; y la segunda, que de la interceptación de un número de teléfono aparezcan informaciones relevantes para otros hechos ilícitos que no ameriten pena de crimen. ${ }^{53}$ Conforme a lo señalado, podemos apreciar que la clasificación atiende sólo a si los hechos nuevos que se obtienen son constitutivos de un delito que merezca o no pena de crimen, es decir, atiende a la gravedad del delito. Con esto se dejan de lado los demás supuestos que la doctrina alemana reconoce, no importando para estos efectos, si la información nueva que se adquiere respecto a los delitos cometidos se refiere o no a personas cuyos equipos telefónicos han sido interceptados.

\footnotetext{
${ }^{52}$ Sobre el borrado y la destrucción de las cintas magnetofónicas que contienen los datos obtenidos mediante la interceptación telefónica, los sistemas de Derecho comparado más cercanos a nuestra cultura procesal han previsto diversas formas de enfrentar dicha cuestión. En Alemania, por ejemplo, las grabaciones se deben destruir cuando dejan de ser necesarias, dejándose constancia escrita de la destrucción $\left(\S 100\right.$ b, n ${ }^{\circ} 6$ de la StPO); en Italia, los registros de las interceptaciones se conservarán hasta que la sentencia ya no esté sujeta a impugnación, es decir, hasta que se encuentre firme o ejecutoriada (art. 269, $\mathrm{n}^{\mathrm{o}} 2$ 2, CPPI). En España, por último, la L.O no 13/2015, de 5 de octubre de 2015, que modificó la Ley de Enjuiciamiento Criminal LECrim- para el fortalecimiento de las garantías procesales y la regulación de las medidas de investigación tecnológica, creó el nuevo artículo 588bis, letra $\mathrm{k}$, el cual señala: "una vez que se ponga término al procedimiento mediante resolución firme, se ordenará el borrado y eliminación de los registros originales que puedan constar en los sistemas electrónicos e informáticos utilizados en la ejecución de la medida. Se conservará una copia bajo custodia del secretario judicial".

${ }_{53}$ MARCAZZOLO AWAD, Ximena, "Hallazgos casuales en relación con los delitos de tráfico ilícito de drogas", Revista Jurídica del Ministerio Público n³4 (abril 2008), pp. 150-159, p. 150.
} 
En primer lugar, nos haremos cargo del primer supuesto, es decir, el caso en que de la interceptación telefónica se capta información relevante para hechos que merecen pena de crimen. De acuerdo a la interpretación que le han dado los fiscales del Ministerio Público, el legislador acepta la validez de la prueba obtenida a propósito de un descubrimiento fortuito al momento de ejecutarse la medida de interceptación de comunicaciones, así como también da la posibilidad de ser utilizada en un nuevo caso. ${ }^{54}$

A juicio nuestro, esta interpretación nos parece preocupante, pero susceptible de matizar. En primer lugar, como señalábamos, no se atiende a si se trata de personas concernidas por la medida de intervención telefónica, o de terceros ajenos a dicha diligencia intrusiva. Haciendo esta distinción, si se trata de un delito cometido por un sujeto pasivo de la interceptación, sólo en el caso de que no se haya iniciado un procedimiento penal por los hechos escuchados casualmente, nos parece que es dable que sirva como fundamento para el inicio de una nueva investigación por dicho delito, mas no que dichos antecedentes sean incorporados a la investigación actual. Ahora bien, conforme al tenor del inciso final del artículo 223 del CPP, si se trata de un hecho nuevo que dé cuenta de un delito que merezca pena de crimen y, además, se siga actualmente una investigación penal por dicho delito, nos parece aceptable que los antecedentes escuchados fortuitamente sean incorporados a dicho procedimiento paralelo. Bajo nuestro respecto, este sería el único supuesto de descubrimiento casual que nuestro ordenamiento jurídico permite, es decir, tratándose de un hecho nuevo relativo a un delito que merezca pena de crimen y que ya se encuentre iniciado un procedimiento por tal delito.

Tratándose de un tercero ajeno a la medida, nos parece alarmante el hecho de que se considere que pueda utilizarse lo pesquisado como evidencia en el procedimiento actual, pues se vulnera el derecho fundamental del aludido $\mathrm{y}$, conforme a lo expuesto anteriormente, carece de grado de conexión subjetiva, con la medida de intervención inicial.

En segundo término, nos parece grave que esta forma de hacer lectura al inciso final del artículo 223 del CPP permita concluir que los antecedentes recabados a propósito de un hallazgo casual pueden ser incorporados como medios de prueba sin siquiera cuestionarse, al menos, la legalidad de la diligencia. En este tema, consideramos que estamos en presencia de un supuesto de prueba ilícita obtenida con vulneración de garantías, al no contar con la debida orden judicial que resguarde el derecho vulnerado. Cabe recordar que es el juez de garantía el encargado de velar por los derechos fundamentales del imputado (y terceros, en este caso) no sean vulnerados, sino sólo cuando en los casos excepcionales, se autorice.

No obstante, como indicamos, estimamos que estos datos adquiridos pueden ser los que dan origen a una nueva causa, a un nuevo caso (siempre que no haya un procedimiento paralelo

\footnotetext{
${ }^{54}$ Así lo podemos apreciar en MARCAZZOLO, "Hallazgos", cit. nota ${ }^{\circ}$ 53, p. 150; ZAVIDICH, Carolina, "Prueba ilícita -exclusión- escuchas telefónicas", Revista Jurídica del Ministerio Público n48 (2011), pp. 125-136, p. 134.
} 


\section{Polít. Crim. Vol. 14, No 28 (Diciembre 2019), Art. 4, pp. 152-185. [http://politcrim.com/wp-content/uploads/2019/10/Vol14N28A4.pdf]}

ya iniciado, puesto que estos antecedentes podrán ser incorporados a dicho procedimiento); constituiría una notitia criminis acerca de un nuevo delito, ${ }^{55}$ y para eso, hay que tener en cuenta lo que dispone el artículo 175 del CPP, el cual enumera una serie de personas que están obligadas, por ley, a denunciar. Dentro de este catálogo se encuentran las policías, que serán quienes, normalmente, escuchen las grabaciones, dándose noticia de su acaecimiento. Estos estarán obligados a denunciar el delito, puesto que cae sobre ellos una obligación legal, consagrada en el artículo 177 del CPP que, en caso de no cumplirla, incurrirán en responsabilidad penal.

Estas conclusiones a las que llegamos no son baladíes, puesto que es el mismo artículo 223 del CPP el que se remite a los requisitos de procedencia generales para la interceptación de comunicaciones telefónicas, al prescribir, en su parte final: "de las cuales se podrá hacer uso conforme a las normas precedentes". Dicho esto, no cabe sino concluir que se refiere a las normas que regulan las intervenciones telefónicas, en particular, el artículo 222 del CPP. Es en esta disposición en la que se mencionan, en primer lugar, los requisitos de procedencia de la medida, siendo lo más importante la orden judicial que lo autorice, la cual establece, por mandato legal, la forma de practicar la diligencia, su oportunidad, la persona afectada, y su duración; constituyendo esto un límite de acción y, en caso de ser excedido, la medida decaerá en ilegítima. No obstante, estimamos que el artículo 223 inciso final del CPP, consagra la posibilidad de utilizar los antecedentes recabados por medio de un descubrimiento ocasional, sólo si ya se encuentra en curso un procedimiento por el delito nuevo que merezca pena de crimen, de modo que su ámbito de aplicación queda constreñido a este único supuesto.

Respecto a la segunda hipótesis de hallazgo casual propuesto, conforme a la cual de la interceptación de un número de teléfono aparezcan informaciones relevantes para otros hechos ilícitos que no ameriten pena de crimen (es decir, delitos que merezcan pena de simple delito), estimamos que, por no tratarse de un delito de tal gravedad, no puede sino ser desechado cualquier tipo de antecedente recabado, puesto que uno de los requisitos que establece el artículo 222 del CPP es, precisamente, que se trate de delitos que merezcan pena de crimen; aun cuando se encuentre iniciado un procedimiento por tal delito nuevo o no. Ahora bien, en cuanto a ser considerados hechos fundantes de una nueva investigación, consideramos que es perfectamente posible, teniendo como resguardo que los antecedentes no podrán ser incorporados como evidencia dentro del nuevo procedimiento.

Ahora bien, a pesar que los hallazgos casuales pueden presentarse también en el ejercicio de cualquiera otra medida intrusiva, lo cierto es que nuestro legislador buscó con ambas normas denotar lo que ya había pregonado ínsitamente en el artículo 9 del CPP: evitar que el órgano encargado de la persecución penal burle las exigencias legales para la autorización judicial de diligencias de investigación y, de esta forma, restrinja derechos fundamentales ${ }^{56}$ mediante la presentación de solicitudes aparentemente orientadas a acreditar un hecho cuando en realidad lo que se busca es probar otro.

\footnotetext{
${ }^{55}$ MONTERO, La intervención, cit. nota $\mathrm{n}^{\circ} 28, \mathrm{p} .198$.

${ }^{56}$ La jurisprudencia de los tribunales constitucionales de algunos países de Europa establece, con carácter general, la correspondencia entre la idea de la conformidad constitucional, exigible a toda medida estatal que incide sobre derechos fundamentales, y la expresión "restricción” o "limitación" de tales derechos. Dicha
} 
Así y todo, nuestros tribunales de justicia han interpretado de diversas y variadas formas tal finalidad. En efecto, en algunos fallos se ha sostenido que los hallazgos casuales, dado su carácter impensado o no previsible, por sí solos no evidencian la comisión de un delito en un grado de certeza suficiente, sino que se trata de simples sospechas de un ilícito. De ahí que, en todos aquellos casos en los cuales aparezcan antecedentes fácticos que pudieran estar relacionados con la existencia de otro hecho punible distinto del que constituyere la materia principal del procedimiento, no se verifique necesariamente un hallazgo casual en los términos de las normas antes analizadas, sino de una actuación de oficio desplegada por la policía que actúa de forma legal ante un hecho delictivo sorprendido en flagrancia. De este modo, en virtud de los artículos 83 y 130 del Código Procesal Penal, cabría estimar que los funcionarios policiales, actuando, por ejemplo, en virtud de una orden de entrada y registro, "deben asir los objetos encontrados que son en sí, constitutivos de crimen o simple delito, a diferencia de aquellas cosas que se encuentran en un lugar y permiten la sospecha del acaecimiento de un hecho punible. Esta distinción surge de la forma en la cual se encuentra redactada la disposición, dado que resulta evidente que existen objetos que la mera tenencia de ellos da cuenta de un injusto, mientras que hay que son meramente indiciarios de lo mismo no requiriéndose, en consecuencia, de una nueva orden judicial que autorice la restricción". 57 Efectivamente, si bien no se debe confundir las dos instituciones,

vinculación se ha argumentado con la afirmación, generalmente admitida por los mencionados tribunales, que ni los derechos fundamentales son absolutos, ni tampoco sus límites. Derechos y límites se sitúan en un régimen de "concurrencia normativa", en el sentido de que actúan recíprocamente, si bien, ante la posición privilegiada que los derechos fundamentales ocupan en nuestro ordenamiento, debe restringirse el alcance de las normas limitadores que actúan sobre ellos o, lo que es lo mismo, los límites deben interpretarse restrictivamente y en el sentido más favorable a la eficacia y esencia de dichos derechos. Así las cosas, como noción de restricción de derechos fundamentales no ha sido suficientemente elaborada por nuestra doctrina, tal circunstancia conduce a la búsqueda de tal concepto en otros ordenamientos jurídicos, como el alemán, donde ha sido objeto de elaboración doctrinal, con el propósito de incorporar el término equivalente a nuestro ordenamiento jurídico. De conformidad con la mencionada concepción doctrinal germana, las medidas restrictivas de derechos fundamentales pueden definirse como aquellas intromisiones vulneradoras prima facie del ámbito de protección de los derechos fundamentales, lo que conforma el supuesto de hecho de dichos derechos que precisan, por este motivo, de justificación de acuerdo con el principio de proporcionalidad. Sobre el particular, con mayor detenimiento, Cfr. SCHMALZ, Dieter, Grundrecht ( $3^{\circ}$ Auf.), Baden-Baden: Nomos, 1997, pp. 55 y ss.; ECKHOFF, Rolf, Der Grundrechtseingriff, Kölhn: Heymanns, 1992, p. 21; y PIEROTH, Bodo;SCHLINK, Bernhard, Grundrecht. Staatasrecht II, Heidelberg: CF. Müller, 1989, pp. 336-337.

${ }^{57}$ Tribunal de Juicio Oral en lo Penal de San Antonio, causa RUC 0700392681-2, del 5 de diciembre de 2007. En sentido casi indéntico, tambien se ha sostenido: " $2^{\circ}$ Que corresponde determinar si el hallazgo de un arma y de documentación al parecer falsa, son hechos que por sí solos configuran la comisión de un delito en términos que tratándose de un caso de flagrancia de aquellos contemplados en el artículo 130 del Código ya señalado (...). En efecto si en poder de un particular se encuentra un arma de fuego y requerido para que exhiba la documentación que lo autoriza para su tenencia y porte, no lo hace, es de toda lógica inferir que se configura alguna de las infracciones que penaliza la ley sobre control de armas y por ello se trata de la flagrancia en la comisión de un delito, en conformidad a lo que señala el artículo $130 \mathrm{~N}^{\circ} 1$ del referido Código. No se trata de un objeto o documento indiciario de la comisión de algún delito, sino de la materialidad misma del ilícito, por lo que asimilar la situación producida a aquella descrita en el artículo 215 ya citado, no es pertinente. Menos aún lo es, el pretender que la policía deba inhibirse de actuar en la forma que le es exigible, si en el transcurso de una diligencia autorizada por la autoridad judicial, constata hechos, 


\section{Polít. Crim. Vol. 14, No 28 (Diciembre 2019), Art. 4, pp. 152-185. [http://politcrim.com/wp-content/uploads/2019/10/Vol14N28A4.pdf]}

se debe tener presente que en los delitos de posesión, ${ }^{58}$ es decir, tipos penales en los cuales el verbo rector utilizado por el legislador consiste en una conducta que se consuma con la sola tenencia de algo (ej. delitos de posesión de material pornográfico infantil, porte ilegal de armas, etc.) ambas instituciones encuentran estrechamente relacionadas.

Otra interpretación, y que avala también la referida actuación en situación de flagrancia, se funda en que la policía estaría dotada de cierta autonomía para desarrollar actuaciones que tiendan al éxito de la investigación, conciliando su eficacia con el respeto de los derechos fundamentales de las personas, razón por la cual ningún funcionario policial puede "cerrar los ojos" frente a una "notitia criminis" incidentalmente descubierta en una intervención dirigida a otro fin. Por tal motivo, siempre que la evidencia obtenida con ocasión de una medida intrusiva haya excedido el "ámbito objetivo" de la investigación bajo cuyos presupuestos fue concedida, se entienda que dicha prueba es válida $\mathrm{y}$, por consiguiente, puede hacerse valer en juicio, siempre y cuando la misma resulte justificada con arreglo a los criterios de urgencia y necesidad y que se cumpla el requisito de proporcionalidad al ponderar los intereses en juego en el caso concreto. De este modo, con los descubrimientos inminentes o casuales se permitiría precisamente "la incorporación de prueba eventualmente derivada de otra, aún contaminada inicialmente y en que está en juego la buena fe y precisamente la proporcionalidad y trascendencia". 59

Se ha sostenido que conforme al principio de especialidad, no es admisible decretar una incautación o intervención para tratar de descubrir, en general, sin la adecuada precisión, actos delictivos que se funden en una auténtica autorización prácticamente en blanco. Por consiguiente, la actuación de la policía debiese quedar circunscrita a la búsqueda de antecedentes relacionados con el delito objeto de la resolución que autorizó la medida, siendo "el deber de los funcionarios policiales de obtener una resolución judicial para la incautación de evidencia no ligada con la pesquisa". 60 Esto porque, no obstante la modificación introducida por la Ley $\mathrm{N}^{\circ}$ 20.931, habría que entender que para los hallazgos casuales aún resulta gravitante el artículo $9^{\circ}$ del CPP, que dispone que las actuaciones del procedimiento que priven al imputado o a un tercero de los derechos que la Constitución asegura, o los restringieren o perturbaren, requerirán siempre de autorización judicial previa.

que si bien no guardan conexión con ella, se están ejecutando y son constitutivos de delitos (...)”. Corte de Apelaciones de Santiago, causa rol 753-2007, de 19 de abril de 2007.

${ }^{58}$ Sobre el tema ver por todos: COX LEIXELARD, Juan Pablo, Delitos de posesión, Motevideo: BdeF, 2012, passim.

${ }^{59}$ Así se ha pronunciado la Ilma. Corte de Apelaciones de San Miguel, causa rol № 1059-2015, de 6 de julio de 2015. En idéntico sentido, Ecxma. Corte Suprema, causa rol N 2576-2011, de 11 de mayo de 2011.

${ }^{60}$ Así lo ha señalado la Ilma. Corte de Apelaciones de Concepción, en la causa rol $\mathrm{N}^{\circ} 383$, de 30 de mayo de 2016, y en la causa rol $\mathrm{N}^{\circ}$ 376, de 12 de mayo de 2017. Lo mismo ocurrió por parte de la Excma. Corte Suprema, como por ejemplo, en la causa rol $\mathrm{N}^{\circ} 18.011$, de 13 de agosto de 2014; en la causa rol $\mathrm{N}^{\circ} 2.304$, de 1 de abril de 2015; en la causa rol $N^{\circ} 40.698$, de 20 de noviembre de 2017. 
No hay que olvidar el mandato general que establece el artículo $5^{\circ}$ inciso $2^{\circ}$ del $\mathrm{CPP}^{61}$, acerca de la legalidad de las medidas privativas o restrictivas de la libertad. Vale decir, que la interpretación que se ha de tener respecto de los preceptos que importan una privación o restricción de la libertad o - esta es la frase importante para este caso- de otros derechos del imputado -en este caso, el derecho a la intimidad-, debe ser hecha de manera restrictiva. Esto es de suma relevancia, puesto que no sólo se refiere a los supuestos de restricción de libertad, sino de derechos en general.

Estimamos que estas deben ser las interpretaciones que se le deben dar a la norma en comento, ya que de esta manera se salvaguardan los derechos fundamentales de los afectados. Sólo el juez es quien debe permitir la vulneración de derechos, y esto se materializa con la autorización judicial que el fiscal solicite cuando sea necesario, idóneo y proporcional a la realización de una diligencia intrusiva de investigación.

En síntesis, hay que distinguir si quien cometió el delito nuevo descubierto es un sujeto pasivo de la medida o un tercero extraño. Aquí deberá desecharse cualquier antecedente escuchado por carecer de conexión subjetiva, aun cuando la disposición en comento no realiza ninguna distinción. Ahora bien, si se está frente a un sujeto pasivo de la medida intrusiva de investigación, habrá que hacer la siguiente distinción:

- Si se trata de informaciones relevantes relativas a un hecho que pudiera constituir un delito que merezca pena de crimen, y hay un procedimiento iniciado: el hallazgo casual es válido y los antecedentes recopilados podrán incorporarse al procedimiento paralelo en curso.

- Si se trata de datos nuevos relativos a un hecho que constituyere un delito que merezca pena de crimen, pero no hay un procedimiento paralelo en curso: el hallazgo fortuito se configura como una notitia criminis.

- Si se trata de nuevos antecedentes relativos a un hecho que constituya un delito que no merezca pena de crimen, y hay un procedimiento iniciado: el descubrimiento fortuito constituye una notitia criminis.

- Si se trata de conocimientos nuevos acerca de un hecho que no merezca pena de crimen y se encuentra un procedimiento iniciado, deberán desecharse todo antecedente obtenido y no tomarse en consideración.

\footnotetext{
61 "Las disposiciones de este Código que autorizan la restricción de la libertad o de otros derechos del imputado o del ejercicio de alguna de sus facultades serán interpretadas restrictivamente y no se podrán aplicar por analogía".
} 


\section{Los hallazgos casuales de las comunicaciones digitales en Chile: problemas que plantean y posibles formas de solución}

\subsection{La diligencia de retención e incautación de correspondencia}

Se entiende por retención e incautación de correspondencia la diligencia intrusiva decretada por el juez de garantía, a solicitud del ministerio público, por la que se ordena a los funcionarios policiales que procedan a la retención e incautación de la correspondencia postal, telegráfica o de otra clase del imputado con el objeto que sea revisada por el fiscal a cargo de la investigación. ${ }^{62}$

Se decretará por el juez por resolución fundada del juez de garantía, a petición del fiscal, cuando se trate de correspondencia postal, telegráfica o de otra clase y los envíos dirigidos al imputado o remitidos por él, cuando se presumiere por especiales circunstancias, que fueren de utilidad para la investigación. No obstante lo anterior, el fiscal sólo podrá conservar la correspondencia o los envíos que tuvieren relación con los hechos investigados (artículo 218 del CPP).

Ahora bien, hay que precisar que al hablar de correspondencia, lo cual es una forma de comunicación, se está frente a un extenso abanico por el cual se puede llevar a cabo una relación emisor-receptor. En particular, corresponde ocuparse de la correspondencia electrónica. Los correos electrónicos constituyen una forma de comunicación, un sistema mediante el cual se puede enviar y recibir mensajes desde una casilla de correo de una persona hacia la casilla de correo de otra. ${ }^{63}$ Ahora bien, el computador es el lugar de recepción del mensaje y donde éste es reagrupado automáticamente, para posibilitar su lectura. El correo electrónico es un mecanismo de transmisión caracterizado por ser: un medio electrónico (utiliza medios electrónicos de gestión y transporte); asíncrono (no necesita sincronía de envío y recepción); ubicuo (permite su acceso en diferentes lugares); digital: (utiliza información digitalizada); informático: (está en relación con las tecnologías de la información). ${ }^{64}$ Es, por esa razón, que las características que destacan de todo correo electrónico es su asincronía, es decir que no necesita sincronía de envío y recepción; y, ciertamente su ubicuidad, esto es, permite su acceso en diferentes lugares.

Así las cosas, el correo electrónico o email, es un medio de comunicación que no tiene un soporte físico, sino más bien, digital, es de carácter virtual, y la forma en que se puede acceder a su información es a través de un computador, en principio. Éste no se agota en el ordenador mismo, sino que aquél viene a ser el medio que permite su recepción y lectura.

Al encontrarse frente a una forma de comunicación, esta es objeto de protección del ordenamiento jurídico, en particular por el artículo $19 \mathrm{~N}^{\circ} 5$ de la CPR, al consagrar la inviolabilidad de las comunicaciones privadas. Por ello, resulta ser necesario para una

\footnotetext{
${ }^{62}$ En un sentido similar: GIMENO SENDRA, Vicente, Derecho Procesal Penal, Madrid: Colex, 2004, p. 398.

63 GALDÓS, Jorge Mario, "Correo electrónico, privacidad y daños”, Alfa-Redi: Revista de Derecho Informático $\mathrm{n}^{\circ} 044$ (2002), p. 9.

${ }^{64}$ GALDÓS, “Correo Electrónico”, cit. nota n 63, p. 9.
} 
eventual realización de una diligencia intrusiva como la retención e incautación de correspondencia, la pertinente autorización judicial, en forma previa, por parte del juez de garantía, en términos tales que de no contarse con aquélla, o bien, si se excediere de los términos en los cuales está otorgada y, tal como el Código Procesal Penal indica, la prueba obtenida sin los requisitos establecidos por la ley, como en el caso de que se hubiere obtenido con la vulneración de las derechos constitucionales del imputado, ésta adolecería de ilicitud, conforme a lo establecido en el artículo 276 del CPP.

En Chile, la utilización del correo electrónico como prueba en juicio se encuentra estrechamente vinculada al debido proceso y la prueba ilícita, por sus características particulares y su forma de obtención. Así, la protección del correo electrónico ha sido tratada en distinta áreas. En este sentido, el Consejo para la Transparencia ha considerado que el artículo $19 \mathrm{~N}^{\circ} 5$ de la CPR entrega protección a los correos electrónicos ${ }^{65}$.

Cabe mencionar que, ante una incautación de correspondencia, sea epistolar, electrónica o de cualquier otra índole, podemos estar frente a una vulneración de derechos fundamentales distintos, pues habrá que estar a qué es a lo que efectivamente se accede. En primer lugar, cabe señalar que no es lo mismo acceder a los correos electrónicos del imputado que al contenido de éstos. En nuestra opinión se trata de garantías distintas las vulneradas en una y otra situación; en la primera, se ve una vulneración del derecho de propiedad, asegurado en el artículo $19 \mathrm{~N}^{\circ} 24$ de la CPR, que tiene por finalidad asegurar la evidencia, de modo que no llegue a manos del afectado por la medida intrusiva. Respecto de la segunda, es decir, la incautación de correspondencia (y también la interceptación de comunicaciones), es una diligencia intrusiva de investigación que afecta el derecho constitucional de la intimidad y la inviolabilidad de las comunicaciones privadas, resguardados en los numerales 4 y 5 del artículo 19 de la CPR.

Así las cosas, si lo que se pretende es acceder al contenido de un correo electrónico que no se encuentra abierto y en el disco duro del computador incautado legítimamente por orden judicial, el Ministerio Público necesitará de una autorización de apertura de correspondencia, además de la orden de entrada, registro e incautación. Por otro lado, en los Estado Unidos de América es discutible, para un sector de la doctrina, que la institución del "Plain View"66 (hallazgo casual) tenga aplicación en la incautación de dispositivos informáticos. En efecto, la doctrina en comento consiste en que si en la ejecución de una diligencia de entrada, registro e incautación los agentes policiales se encuentran, a simple vista o por medio de la utilización simple de sus sentidos con elementos de la comisión de otro delito distinto, están facultados para proceder al secuestro o incautación del objeto en cuestión. ${ }^{67}$ Con todo, en materia de evidencia digital dada su naturaleza no corpórea, no existe forma de apreciar su apariencia ilícita sin la revisión de todos los datos del

\footnotetext{
${ }^{65}$ CONSEJO PARA LA TRANSPARENCIA, Decisión Amparo Rol N C406-11 del año 2012. Disponible en: 〈<http://extranet.consejotransparencia.cl/web_scw/Archivos/C406-11/C406-11_decision_web.pdf $>$.

${ }^{66}$ Ver por todos: DRESSLER, Joshua; MICHELS, Alan C, Understanding Criminal Procedure (Vol. I Investigation), Carolina Academic Press: Durham, 2017, pp. 227 y ss.

${ }^{67}$ DRESSLER / MICHELS, Understanding, cit. nota n 66 , pp. 228 y ss.
} 


\section{Polít. Crim. Vol. 14, No 28 (Diciembre 2019), Art. 4, pp. 152-185. [http://politcrim.com/wp-content/uploads/2019/10/Vol14N28A4.pdf]}

dispositivo electrónico, posibilitando en los hechos una búsqueda irrestricta en todo el acervo digital de la persona sometida a la diligencia. ${ }^{68}$

\subsection{Las autorizaciones voluntarias en Derecho Procesal Penal}

Tanto el allanamiento de un inmueble, como la incautación de especies, son diligencias que pueden ser válidamente realizadas, en términos generales, si se cuenta con la autorización del afectado por la medida (artículos 205 inciso $1^{\circ}$ y 217 inciso $1^{\circ}$, ambos del CPP). Mediante ambas disposiciones, el legislador "renuncia" a la protección del derecho a la inviolabilidad del hogar, de la privacidad y la propiedad (artículo $19 \mathrm{~N}^{\circ} 4^{\circ}, 5^{\circ}$ y 24 de la CPR), en aquellos casos en que se cuenta con la anuencia del afectado. Esta autorización, como sea, o bien habilita para la vulneración legítima de la garantía esencial o en su defecto, podemos entender que la hace desaparecer, ya que el acto voluntario recaería sobre una esfera de derechos en principio disponible.

No obstante ser el consentimiento la línea divisoria entre una legítima medida intrusiva investigativa y una violación estatal de derechos fundamentales y ergo, lo que separa aguas entre la prueba admisible y aquella considerada ilícita, no se le ha dedicado a éste mayor atención por nuestro legislador procesal penal. Lo peligroso de la omisión, huelga señalarlo, es que el control judicial tienda a asentarse en una simplificación meramente formal, en términos tales que sea considerada legítima la medida que aparezca respaldada por una rúbrica del afectado o por alguna mención ritual en las actas policiales, mientras que ilegítima la que no encuentre su respaldo en tales evidencias. ${ }^{69}$ La tentación de aceptar esta caricaturización del problema, radica en la relevante dificultad probatoria que puede implicar el acreditar sucesos generalmente probados en ambientes protegidos o de accesos restringidos, y por otro lado, conectados con el fuero interno de un ciudadano.

Sin embargo, asumir la responsabilidad de una aplicación efectiva de las garantías constitucionales y la subordinación del poder coercitivo del Estado a los derechos esenciales, demanda no conformarse con una evaluación de las formas sino avanzar hacia la elaboración de un estándar que considere aspectos cualitativos relacionados con el grado de información y de libertad con que se construyó el consentimiento.

Bien puede, fundadamente, objetarse las circunstancias en que se concedió la autorización por el afectado, arguyendo la existencia de una presión indebida, de una amenaza velada o la tergiversación de los antecedentes que la rodean o justifican. Es posible concebir que por un excesivo entusiasmo de los agentes de investigación, su premura, mala fe, u otra causa, el afectado con la medida que renuncia a su garantía, no llegue a entender nunca cabalmente su desprendimiento y la posibilidad que tiene de negarse al requerimiento.

\footnotetext{
${ }^{68}$ RAYMING, Chang, "Why the plain view doctrine should not apply to digital evidence", Suffolk Journal of Trial and Appellate Advocacy, Vol. 12 (2007), pp. 31-67, passim.

${ }^{69}$ Véase MAIER, Julio BJ., Derecho Procesal Penal argentino, Buenos Aires: Editorial Hammurabi, 1989, p. 461. El autor advierte, para el derecho argentino, el riesgo latente de terminar reduciendo las garantías involucradas a la mera constatación de la existencia de fórmulas verbales burocráticas.
} 
En efecto, tratándose de la declaración del imputado, el ordenamiento procesal ha exigido que por regla general la renuncia al derecho a guardar silencio se haga contando con un defensor, o en su defecto, ante la presencia del fiscal, o bajo su responsabilidad (artículo 91 del CPP). A su turno, por su sola calidad de imputado, deberá ser informado de manera específica y clara de los hechos que se le imputan y que en caso de renunciar a su derecho a guardar silencio ello no podrá acarrearle ninguna consecuencia adversa (artículo 93 letras a) y g) del CPP). En el mismo sentido, se exige por el legislador que "si el imputado se allanare a prestar declaración....antes de comenzar el físcal le comunicará detalladamente cuál es el hecho que se le atribuyere, con todas las circunstancias de tiempo, lugar y modo de comisión, en la medida conocida, incluyendo aquellas que fueren de importancia para su calificación jurídica, las disposiciones legales que resultaren aplicables y los antecedentes que la investigación arrojare en su contra" (artículo 194 del CPP.). Como se aprecia, tratándose de la renuncia a una garantía procesal como lo es el derecho a guardar silencio, el legislador adopta múltiples medidas tendientes a asegurarse la calidad del consentimiento, arbitrios que van desde asegurarse la presencia por regla general de un letrado, que asegure el otorgamiento de información de mejor calidad, pasando por el señalamiento de los antecedentes que obran en contra del imputado que justifican direccionar la investigación en su contra, hasta la existencia de fórmulas sacramentales, como la del artículo 93 letra g) del Código Procesal Penal, exigencia que persigue la entrega de una advertencia informativa integra y cabal, que no pueda ser cercenada por la discrecionalidad o criterio del funcionario. No parece razonable colegir que tratándose de otras garantías fundamentales, consagradas incluso de manera expresa por el ordenamiento constitucional y de acciones también susceptibles de vincular al sujeto a un delito, el legislador ha renunciado a cualquier control de calidad sobre la voluntariedad. Siguiendo a Rives, para que exista consentimiento, en aquella parte que por ahora nos interesa, éste debe ser prestado "(...) consciente y libremente. Lo cual requiere... que no esté invalidado por error, violencia o intimidación de cualquier clase [y] que no se condicione, a circunstancia alguna periférica, como promesas (...)".70

Como es posible advertir, el legislador expresamente distingue entre la incautación de correspondencia y de documentos privados, fijando, para cada uno de los supuestos señalados, la procedente medida intrusiva que cabe a su respecto. Es posible concluir que, en atención a los requisitos de procedencia señalados en los artículos 217 y 218 del Código Procesal Penal, respectivamente, la correspondencia goza de un mayor grado de protección, frente a los objetos y documentos susceptibles de incautación o retención.

La renuncia a la garantía de inviolabilidad del hogar, así como también a cualquier otra prerrogativa susceptible de ser cedida, coherente con la relevancia del derecho del que el individuo se desprende, sólo podrá ser concedida en condiciones que aseguren la adecuada comprensión de la relevancia procesal que puede tener la diligencia, su naturaleza, la posibilidad de negarse a la misma y la exclusión de cualquier tipo de presión o violencia para lograr la aquiescencia del afectado. Así también, y conforme se ha venido desarrollando, si bien no puede establecerse ex ante que el consentimiento otorgado por

\footnotetext{
${ }^{70}$ RIVES SEVA, Antonio, La diligencia de entrada y registro domiciliario, Barcelona: Bosch, 2004, pp. 6566.
} 


\section{Polít. Crim. Vol. 14, No 28 (Diciembre 2019), Art. 4, pp. 152-185. [http://politcrim.com/wp-content/uploads/2019/10/Vol14N28A4.pdf]}

un sujeto detenido no sea válido, éste resulta al menos, en principio, sospechoso, por las condiciones en que éste se concede, debiendo por ello hacerse un examen de la voluntariedad que considere todos los factores de presión psicológica y anímicos a los que puede haber estado sometido el sujeto detenido. ${ }^{71}$

Como evidente corolario de lo anterior, si quien invoca la renuncia a una garantía básica, en principio libre de cualquier injerencia estatal, no puede probar que ella se realizó en condiciones de libertad e información de un nivel tal que justifique un consentimiento válido, la prueba obtenida como consecuencia del allanamiento de recinto cerrado, deberá ser excluida de consideración en el juicio oral.

En atención a lo señalado anteriormente, respecto a los correos electrónicos, que gozan de protección constitucional al tratarse de una forma de comunicación privada, tutelada por el artículo $19 \mathrm{~N}^{\circ} 5$ de nuestra Carta Fundamental, es que se hace necesario que las autorizaciones que voluntariamente presten los imputados, en orden a permitir la vulneración de este derecho, éstas deben ser expresadas de modo preciso e inequívoco, que no den, de forma alguna, duda al respecto. Como es sabido, para solicitar una autorización judicial, no es necesario que el derecho fundamental respectivo sea desconocido o sujeto a una privación total; basta que el ejercicio del derecho sea restringido o perturbado, lo que maximiza el rol protector que la ley otorga al juez en cualquier situación de afectación del derecho. Junto con lo anterior, resulta evidente, al tenor literal de la norma, en cuanto a que la autorización judicial debe ser previa, es decir, no es posible afectar de modo alguno el derecho, por parte del órgano que investiga, sin que se cuente con anterioridad con dicha autorización. Dicho de otro modo, la ley prohíbe que se puedan afectar derechos constitucionales de un imputado, sin contar con la autorización previa del juez de garantía.

Se estima que, para efectos de una autorización voluntaria, en conformidad a los artículos 217 y 218 del Código Procesal Penal, debe contemplar el mismo contenido -es decir, debe producirse una suerte de homologación- que tendría una autorización judicial previa, de acuerdo al artículo $9^{\circ}$ Código Procesal Penal. Vale decir, estamos frente a un supuesto de una actuación del procedimiento que prive, restrinja o perturbe al imputado del ejercicio de los derechos que la Constitución asegura. Dicha autorización voluntaria debe ser conferida con un nivel de especificidad tal que no permita actuaciones, por parte del ejecutante de la diligencia intrusiva, que se alejen del consentimiento prestado por el afectado de la medida intrusiva. Es menester indicar que la autorización voluntaria debe bastarse a sí misma, en el sentido de que no puede excederse de sus términos, ya que, al igual que si se tratase de una autorización judicial, el exceso en la actuación de las policías, por ejemplo, constituiría una vulneración de los derechos fundamentales del imputado o del afectado por la medida. Esto traería como consecuencia la exclusión de los antecedentes recopilados en una situación como esta por motivos de ilicitud, conforme a lo dispuesto en el artículo 276 del CPP.

En resumen, para que las policías puedan tener acceso a los correos electrónicos de los imputados deben, ya sea contar con la autorización voluntaria del imputado afectado por la

\footnotetext{
${ }^{71}$ NÚÑEZ OJEDA, Raúl; CORREA ZACARÍA, Claudio, "La prueba ilícita en las diligencias limitativas de derechos fundamentales en el proceso penal chileno. Algunos problemas", Ius et Praxis n²3 (2017) 1, pp. 195-246, p. 227.
} 
diligencia intrusiva, titular de dichos correos, o bien, con la respectiva autorización judicial que legitime la diligencia intrusiva conducente a obtener antecedentes útiles para la investigación oficial en curso. Aquí al igual que en caso anterior tampoco es posible utilizar la figura del hallazgo casual como mecanismo para subsanar la ausencia de autorización expresa del imputado. En efecto, tal como señalo en el apartado 4.1, si se admitiera llevaría a que cualquier incautación de un dispositivo informático se transforme en una búsqueda general, habilitada para capturar cualquier evidencia de cualquier delito y que tal evidencia pueda utilizarse válidamente en ese $u$ otro que se inicie como consecuencia de esa evidencia pasando a llevar los derechos y garantías constituciones de los investigados ${ }^{72}$.

\section{Conclusiones}

Según lo expuesto, se puede colegir que durante la etapa de investigación existen ciertas diligencias en las cuales se hace necesario contar con una autorización judicial previa, las denominadas diligencias intrusivas de investigación. Entre éstas encontramos, por ejemplo, la entrada y registro, con la subsecuente incautación y la interceptación de comunicaciones telefónicas, las cuales constituye una afectación grave contra la intimidad del imputado y de terceros y contra el derecho de propiedad, garantizados por nuestra Carta Fundamental.

Para que un juez de garantía pueda ordenar una diligencia limitativa de derechos fundamentales, debe efectuar un juicio de ponderación. Dicho examen pretende mantener el equilibrio entre la eficacia de la persecución penal y la vigencia de los derechos fundamentales de las personas. Para ello, el juez deberá comprobar que la realización de la diligencia sea adecuada para obtener el fin que se pretende (idoneidad); luego, procederá a comparar todas las medidas que se adecúen a ese fin, y elegirá aquélla que sea menos lesiva (necesidad); y finalmente, ponderará si las ventajas de su autorización son correlativas con la vulneración de derechos, o sea, si son proporcionales (proporcionalidad en sentido estricto).

Es frecuente que en el desarrollo de cualquier diligencia intrusiva de investigación judicialmente autorizada, pero en mayor medida en las señaladas anteriormente, se pueda tomar conocimiento de datos o informaciones, o bien, encontrar objetos o documentos relacionados con un delito distinto respecto del cual ha sido objeto de la medida en cuestión. Estos son los denominados hallazgos o descubrimientos casuales o fortuitos. Estos datos o informaciones podrán referirse a hechos que den cuenta de la comisión de un delito distinto del cual se está investigando, o bien, respecto de personas que no han sido sujeto pasivo de la diligencia intrusiva.

Nuestro Código Procesal Penal consagra dos normas relativas a los descubrimientos fortuitos, la de los artículos 215 y 223, para el caso de entrada y registro e interceptación de comunicaciones telefónicas, respectivamente.

\footnotetext{
${ }^{72}$ PETRONE, Daniel, Prueba informática, Ediciones Didot, Buenos Aires, 2015, p. 69.
} 


\section{Polít. Crim. Vol. 14, No 28 (Diciembre 2019), Art. 4, pp. 152-185. [http://politcrim.com/wp-content/uploads/2019/10/Vol14N28A4.pdf]}

La correspondencia privada que mantenga una persona goza de protección constitucional, a través del derecho a la inviolabilidad de las comunicaciones privadas, consagrado en el artículo $19 \mathrm{~N}^{\circ} 5$ de la CPR. Para ser afectada dicho derecho, es necesario que el fiscal que lleva adelante la investigación, solicite una autorización judicial previa, la cual podrá ser decretada por el juez de garantía. Esto incluye a la correspondencia digital.

La correspondencia digital es una de las diversas clases de comunicación que un ciudadano pueda sostener, y su intromisión por parte de agentes investigadores debe ser efectuada según lo dispuesto en el Código Procesal Penal. Este tipo de comunicación privada se caracteriza por ser un medio electrónico, asíncrono, ubicuo, digital e informático. Por tanto, el email consta en un soporte virtual, mas no físico, el cual es distinto y distinguible del mismo por el cual se accede a aquél. En ese orden de ideas, el acceso autorizado a equipos computacionales, entendido como el soporte físico para ingresar a un correo electrónico, no autoriza a los entes persecutores para ingresar a la correspondencia digital por no encontrarse en él, sino que constituye el medio por el cual se accede a ésta.

La autorización del afectado para efectuar una diligencia intrusiva de investigación permite la práctica de la misma, sin que ello devenga en ilicitud por no contarse con autorización judicial para practicarla. No obstante, dicha autorización voluntaria debe ser prestada sin presiones, libre y espontáneamente ante los agentes que la practicarán, como en el caso propuesto. Además, debe ser lo suficientemente precisa y completa, de modo tal que debe producirse una homologación respecto de una autorización que da el juez de garantía. De no contemplarse con estos requisitos, dicha autorización deviene en ilícita.

Finalmente, no parece posible que a través de la institución de los hallazgos causales se pueda subsanar la falta de autorización del juez para la apertura de correspondencia como tampoco la ausencia de autorización expresa del imputado para la revisión de su correo electrónico. 
NÚÑEZ, Raúl; BELTRÁN, Ramón; SANTANDER, Nicolás, “Los hallazgos casuales en las diligencias de incautación e intervención de las comunicaciones digitales en Chile.

Algunos problemas"

\section{Bibliografía}

ALEXY, Robert, Teoría de los derechos fundamentales, $2^{a}$ edición, Trad.: BERNAL PULIDO, Carlos, Madrid: Centro de Estudios Políticos y Constitucionales, 2008.

ALONSO PÉREZ, Francisco, Intervención de las comunicaciones postales, telegráficas y telefónicas. Legislación, comentarios, jurisprudencia, Madrid: Dykinson, 2001.

ÁLVAREZ DE NEYRA KAPPLER, Susana, "Los descubrimientos casuales en el marco de una investigación penal (con especial referencia a las diligencias de entrada y registro en domicilio)", Revista internacional de estudios de Derecho Procesal y Arbitraje, n² (2011), pp. 1-69.

ÁLVAREZ RODRÍGUEZ, José Ramón; RIUS DIEGO, Francisco José, La entrada y registro en lugar cerrado: consideraciones procesales, jurisprudenciales $y$ policiales, Madrid: Tecnos, 2009.

AMBOS, Kai. "Las prohibiciones de utilización de pruebas en el proceso penal alemán fundamentación teórica y sistematización”, Política Criminal n7 (2009), pp. 1-51.

AMBOS, Kai, Beweisverwertungsverbote.: Grundlagen und Kasuistik - internationale Bezüge - ausgewählte Probleme, Duncker und Humblot: Berlin, 2010.

ARMENTA DEU, Teresa, La prueba ilícita (un estudio comparado), Madrid: Marcial Pons, 2011.

ARMENTA DEU, Teresa, Lecciones de Derecho procesal penal, Madrid: Marcial Pons, 2017.

ARNOLD, Rainer; MARTÍNEZ ESTAY, José Ignacio; ZÚÑIGA URBINA, Francisco, “El principio de proporcionalidad en la jurisprudencia del Tribunal Constitucional", Estudios Constitucionales, ${ }^{\circ} 10$ (2012) 1, pp. 65-115.

BARAK, Aharon, Proportionality: Constitutional rights and their limitations, Cambridge: Cambridge University Press, 2012.

BELING, Ernst, Derecho Procesal Penal, Trad.: FENECH, Miguel, Barcelona: Ed. Labor, 1943.

BELING, Ernst, "Las prohibiciones probatorias como límites de la averiguación de la verdad en el proceso penal", en: BELING, Ernst; AMBOS, Kai; GUERRERO, Oscar Julián, Las prohibiciones probatorias, Bogotá: Temis, 2009, pp. 3-56.

BELING, Ernst, Die Beweisverbote als Grenzen der Wahrheitsfindung im Strafprozess, Breslau: Schletter, 1903.

BEULKE, Werner, Strafprozessrecht, Heidelberg: CF. Müller, 2012.

BÖCKENFÖRDE, Ernst- Wolfgang, "Fundamental rights as constitutional principles. On the current state of Interpreting fundamental rights", en: KÜNKLER, Mirjam; STEIN, Tine (eds.), Constitutional and political theory: selected writings, vol. I, Oxford: Oxford University Press, 2017, pp. 235-265.

CAMON, Alberto, Le intercettazione nel proceso penal, Milano: Guiffrè Editore, 1996.

CARBONELL, Miguel, "Presentación. El principio de proporcionalidad y los derechos fundamentales", en CARBONELL, Miguel (coord.), El principio de proporcionalidad en la interpretación jurídica, Santiago: Librotecnia, 2010, pp.1115.

CHIAVARIO, Mario, Diritto Processuale Penale. Profilo instituzionale, Torino: UTET, 2012. 
COHEN-ELIYA, Moshe; PORAT, Iddo, "Proportionality and justification", Law Journal University of Toronto $\mathrm{n}^{\circ} 64$ (2014) 3, pp. 458-477.

CORREA, Carlos, "Más allá de la regla de exclusión: prohibiciones probatorias en el Derecho chileno", Política Criminal, Vol. 13, n 25 (2018), pp. 144-174.

COVARRUBIAS CUEVAS, Ignacio, “Emplea el Tribunal Constitucional el test de proporcionalidad? (128 sentencias del tribunal constitucional en la perspectiva de la jurisprudencia constitucional alemana, de la cámara de los lores y del tribunal europeo de derechos humanos)", Estudios Constitucionales, n¹2 (2014) 1, pp. 163237.

COX LEIXELARD, Juan Pablo, Delitos de posesión, Montevideo: BdeF, 2012.

D'AGOSTINI, Franca, "L'uso scettico della verità", en: FORTI, Gabrio; VARRASO, Gianluca; CAPUTO, Matteo (eds.), «Verità» del precetto e della sanzione penale alla prova del processo, Milano: Jovene editore, 2014, pp. 25 y ss.

DÍAZ CABIALE, José Antonio; MARTÍN MORALES, Ricardo, La garantía constitucional de la admisión de la prueba ilícitamente obtenida, Madrid: Civitas, 2001.

DOMINIONI, Oreste et al, Procedura penale, Torino: Giappicheli, 2010.

DRESSLER, Joshua; MICHELS, Alan C. Understanding Criminal Procedure (Vol. I Investigation), Carolina Academic Press: Durham, 2017.

ECKHOFF, Rolf, Der Grundrechtseingriff, Kölhn: Heymanns, 1992.

ENGLE, ERIC, "The History of the general principle of proportionality: an overview", The Dartmouth Law Journal n¹0 (2012), pp. 1-11.

FUENTES PRINCE, Sebastián, Hallazgo casual de evidencia con ocasión de la práctica de diligencias intrusivas en el marco del proceso penal, Memoria, Valparaíso: Pontificia Universidad Católica de Valparaíso, 2015.

FORDHAM, Michael, "Common law proportionality", Judicial Review n7 (2002) 2, pp. 110-123.

GALDÓS, Jorge Mario, "Correo Electrónico, Privacidad y Daños”, Alfa-Redi: Revista de Derecho Informático $\mathrm{n}^{\circ} 044$ (2002).

GARCÍA, Luis M., "La vigilancia de las telecomunicaciones y otras comunicaciones interpersonales según la jurisprudencia elaborada en torno al Código Procesal Penal de la Nación", en: HAZAN, Luciano A.; PLAZAS, Florencia G. (Coords.), Garantías constitucionales en la investigación penal: un estudio crítico de la jurisprudencia, Buenos Aires: Editores del Puerto, 2006, pp. 308-358.

GEWIRTH, Alan, "Are there any absolute rights?”, The Philosophical Quarterly n`31 (1981) 122, pp. 1-16.

GIMENO SENDRA, Vicente, Derecho Procesal Penal, Madrid: Colex, 2004.

GONZÁLEZ-CUELLAR SERRANO, Nicolás, Proporcionalidad y derechos fundamentales en el proceso penal, Madrid: Colex, 1990.

GONZÁLEZ-MONTES SÁNCHEZ, José Luis, "Reflexiones sobre el proyecto de Ley Orgánica de modificación de la LECrim para el fortalecimiento de las garantías procesales y la regulación de las medidas de investigación tecnológicas", RECPC $\mathrm{n}^{\circ} 17-06$ (2015), pp. 1-41.

GOTTLIEB SVAREZ, Carl, Vorträge über Recht und Staat, Cologne: Westdeutscher Verlag, 1960.

GUTIÉRREZ ZARZA, Ángeles, Investigación y enjuiciamiento de los delitos económicos, Madrid: Colex, 2000. 
JÄGER, Christian, Beweisverwertung und Beweisverwertungsverbote um Strafprozess, CH. Beck: München, 2002.

KHOSLA, Madhav, "Proportionality: An assault. On human rights?: A reply". International Journal of Constitutional Law n॰8 (2010) 2, pp. 298-306.

KONRAD, Sabine, Die Beschlagnahme von Verteidigungsunterlagen, Frankfurt am Main: Peter Lang, 2000.

LA FAVE, Wayne R., "Pinguitudinous Police, Pachydermatous Prey: Whence Fourth Amendment Seizures?", U. Ill. L. Rev. (1991), pp. 729 y ss.

LA FAVE, Wayne R., Search and Seizure, § 9.4, 2004.

LOPERA MESA, Gloria, "Principio de proporcionalidad y control constitucional de las leyes penales", en CARBONELL, Miguel (coord.), El principio de proporcionalidad en la interpretación jurídica, Santiago: Librotecnia, 2010, pp. 211-256.

LÓPEZ-FRAGOSO ÁLVAREZ, Tomás, Las intervenciones telefónicas en el proceso penal, Madrid: Colex, 1991.

LÓPEZ-FRAGOSO, Tomás, "Los descubrimientos casuales en las intervenciones telefónicas como medidas coercitivas en el proceso penal", Derecho y libertades: Revista del Instituto Bartolome de las Casas n² (1993-1994), pp. 81-90.

MACLIN, Tracey, "Black and Blue Encounters - Some Preliminary Thoughts About Fourth Amendment Seizures: Should Race Matter?”, Val. U. Rev. (1991), pp. 243 y Ss.

MAIER, Julio BJ., Derecho Procesal Penal argentino, Buenos Aires: Editorial Hammurabi, 1989.

MARCAZZOLO AWAD, Ximena, "Hallazgos casuales en relación con los delitos de tráfico ilícito de drogas”, Revista Jurídica del Ministerio Público n³4 (abril 2008), pp. 150-159.

MARTÍNEZ PARDO, Vicente, "La práctica de la entrada y registro domiciliario", Revista Jurídica Magestri et Doctores n8 (2002) 2, pp. 204-218.

MONTERO AROCA, Juan, La intervención de la comunicaciones telefónicas en el proceso penal, Valencia: Tirant lo Blanch, 1999.

NADLER, Janice, "No Need to Shout: Bus Sweeps and the Psycology of Coercion”, Sup. Ct. Rev. (2001), pp. 153-222.

NAVARRO BELTRÁN, Enrique, "Notas sobre el Principio de Proporcionalidad en la reciente jurisprudencia constitucional", Revista de Derecho Público, n/e (2018), pp. 309-322.

NIEVA FENOLL, Jordi, Derecho Procesal III. Proceso penal, Madrid, Marcial Pons, 2017.

NÚÑEZ OJEDA, Raúl; CORREA ZACARÍA, Claudio, "La prueba ilícita en las diligencias limitativas de derechos fundamentales en el proceso penal chileno. Algunos problemas", Ius et Praxis n'23 (2017) 1, pp 195-246.

NOZICK, Robert, Anarchy, State and Utopia, Oxford: Blackwell Publishers, 2001.

PARK, Tido, Durchsuchung und Beschlagnahme: $2^{a}$ edición, München: Beck, 2009.

PETRONE, Daniel, Prueba informática, Ediciones Didot, Buenos Aires, 2015.

PIEROTH, Bodo; SCHLINK, Bernhard, Grundrecht. Staatasrecht II, Heidelberg: CF. Müller, 1989.RAYMING, Chang, "Why the plain view doctrine should not apply to 
digital evidence", Suffolk Journal of Trial and Appellate Advocacy, Vol. 12 (2007), pp. 31-67.

RIVES SEVA, Antonio, La diligencia de entrada y registro domiciliario, Barcelona: Bosch, 2004.

RODRÍGUEZ SOL, Luis, Registro domiciliario y prueba ilícita, Granada: Comares, 1998.

ROXIN, Claus - SCHÜNEMANN, Bern, Strafverfahrensrecht, CH. Beck, München, 2010.

ROXIN, Claus, "Zur richterlichen Kontrolle von Durchsuchungen und Beschlagnahmen", Strafverteidiger (1997), pp. 654-656.

SCHMALZ, Dieter, Grundrecht ( $3^{\circ}$ Auf.), Baden-Baden: Nomos, 1997.

SINGH, Mahendra P., German Administrative Law in Common Law Perspective, Berlín: Springer, 1985.

SKLANSKY, David Alan, "On Train May Hide Another: Katz Stonewall, and the Secret Subtext of Criminal Procedure", U.C. Davis L. Rev. (2008), pp. 875 y ss.

SPANGER, Giorgio, "Le criticità della disciplina delle intercettazioni telefoniche", Diritto Penale e Processo $\mathrm{n}^{\circ} 7$ (2016), pp. 921 y ss.

STONE SWEET, Alec; MATHEWS, Jud, "Proportionality balancing and global constitutionalism”, Columbia Journal of Transnational Law nº47 (2008) 73, pp. 68149.

TAPIA, Juan Francisco, "Descubrimientos accidentales en el curso de un registro domiciliario o una interceptación de comunicaciones. El problema de los hallazgos casuales ¿o causales?”, Pensamiento penal nº5 (2009), p. 2, en: $\mathrm{http} / /$ pensamientopenal.com.ar [visitado el 10.07.2018].

TOMKOVICZ, James J., "Beyond Secrecy for Secret's Sake: Toward an Expanded Vision of the Fourth Amendment Privacy Province", Hasting Law Journal n³6 (1985), pp. 645-737.

TONINI, Paolo, Manuale di Procedura Penale, Milano: Giuffrè Editore, 2012

VOLK, Klaus, Curso fundamental de Derecho procesal penal, Trads.: NANZER, Alberto; NÚÑEZ, Noelia; PASTOR, Daniel; SARRABAYROUSE, Eugenio, Buenos Aires: Hamurabi, 2016.

ZAVIDICH DIOMEDI, Carolina, "El registro de vehículos", Revista Jurídica del Ministerio Público ${ }^{\circ} 38$ (marzo 2009), pp. 147-156.

ZAVIDICH DIOMEDI, Carolina, "Prueba ilícita -exclusión- escuchas telefónicas", Revista Jurídica del Ministerio Público n48 (septiembre 2011), pp. 125-136. 